\title{
LA IMAGEN ECONÓMICA DE LA ESPAÑA DE CARLOS III: JOSEPH TOWNSEND, ALEXANDER JARDINE Y LOS ECONOMISTAS ESPAÑOLES*
}

\author{
JOSÉ LUIS RAMÓS GOROSTIZA \\ Universidad Complutense de Madrid $^{\mathrm{a}}$
}

\begin{abstract}
RESUMEN
De entre todos los viajeros británicos que visitaron España en el siglo XVIII, Alexander Jardine y Joseph Townsend fueron los que realizaron los itinerarios más completos y los que más atención prestaron al análisis de la realidad socioeconómica. En su identificación de los problemas económicos específicos coinciden esencialmente con los ilustrados españoles, y particularmente con Campomanes, cuya obra toman como referente básico. Sin embargo, a la hora de enjuiciar la situación económica general, el sistema político y ciertas actitudes gubernamentales basadas aún en planteamientos mercantilistas, surgen discrepancias entre los viajeros y los ilustrados. El gradualismo reformista de estos últimos choca entonces con los planteamientos de transformación profunda del orden político y social que hacían los viajeros. Asimismo, el optimismo de los ilustrados respecto a las posibilidades de crecimiento de la economía española contrastaba con la negativa visión global de los viajeros.
\end{abstract}

* Una versión previa de este trabajo fue presentada al IV Encuentro Ibérico de Historia del Pensamiento Económico celebrado en Lisboa del 8 al 19 de diciembre de 2005. Agradezco mucho los comentarios de Vicent Llombart, Tomás Martínez Vara, Luis Perdices, John Reeder y Manuel Santos, así como las sugerencias de los tres evaluadores anónimos del artículo.

a Departamento de Historia e Instituciones Económicas I, Facultad de Ciencias Económicas y Empresariales, Campus de Somosaguas, 28223 Madrid. Dirección de correo electrónico: ramos@ccee.ucm.es. 
Palabras clave: historia del pensamiento económico, España, siglo XVIII, Ilustración, libros de viajes

\begin{abstract}
Among the British travellers who travelled across Spain in the eighteenth century, Alexander Jardine and Joseph Townsend were those whose itineraries were the most complete and who paid more attention to socioeconomic analysis. Their identification of the specific economic problems coincides broadly with those of Spanish economists, and particularly with those of Campomanes, whose work is considered by them as a basic point of reference. However, there are discrepancies between the travellers and Spanish economists in respect to the general economic situation, the political system and certain government attitudes still based on a mercantilist approach. The reformist gradualism of Spanish economists clashed then with the proposals of the more profound socioeconomic reforms recommended by our travellers. Moreover, the optimism of Spanish economists about growth possibilities of the Spanish economy faced up to the negative overall view of British travellers.
\end{abstract}

Keywords: history of economic thought, Spain, $18^{\text {th }}$ century, Enlightenment, travel books

JEL Classification: B10, B30

\title{
1. INTRODUCCIÓN
}

De entre todos los viajeros británicos que visitaron España en el siglo XVIII, Joseph Townsend (1739- 1816) y Alexander Jardine (?-1799) fueron dos de los más destacados, y en cualquier caso los que mayor interés revisten desde el punto de vista de la historia de los hechos y de las ideas económicas. En efecto, sus obras sobresalen sobre las del resto de sus compatriotas viajeros no sólo por la especial atención prestada a las cuestiones económicas, sino también por su capacidad analítica y por la calidad de la información que contienen. Townsend, prototipo de hombre culto y humanista científico, fue - entre otras cosas - un economista competente, mientras que Jardine, militar de carrera que dominaba perfectamente el castellano, fue un individuo de amplias inquietudes con un importante bagaje en ciencias sociales. Por otra parte, como se verá más adelante, los extensos recorridos geográficos por España de Townsend y Jardine, que tienen lugar durante la misma época —el reinado de Carlos III-, resultan ser en buena medida complementarios, al igual que sucede con sus respectivas aproximaciones 
a los problemas económicos del país. De este modo, entre los dos consiguen aportar una imagen de conjunto bastante completa y coherente.

Este trabajo se centrará precisamente en los aspectos económicos reflejados en la obra que cada uno de estos autores publicó sobre su «viaje ilustrado» por España, un país que había quedado al margen del Grand Tour. En concreto, se analizará su descripción de la situación económica, su diagnóstico de los problemas y sus causas, sus propuestas de remedios generales, y sus valoraciones sobre las políticas económicas vigentes y sobre los intentos de reforma ilustrada. A partir de aquí, el objetivo es comparar la imagen económica de la España de Carlos III que dibujan conjuntamente Townsend y Jardine, con la visión económica de los ilustrados españoles —en especial Campomanes—, identificando coincidencias y discrepancias, e intentando explicar el porqué de estas últimas en función de los elementos que condicionaban la mirada de los dos viajeros.

Existen tres magníficos estudios generales sobre los viajeros británicos en la España del siglo XVIII, pero sus enfoques y objetivos son diferentes a los que aquí se han planteado. Los trabajos de Ana Clara Guerrero (1990) y Consol Freixa (1991) adoptan una perspectiva global, esto es, a partir de los desiguales escritos del heterogéneo grupo de británicos que visitó la Península a lo largo de toda la centuria - formado por más de una veintena de individuos_-, intentan dibujar una imagen sintética del país, incluyendo aspectos políticos, sociales, culturales, económicos y geográficos. Por su parte, el libro de Ian Robertson (1988a) se centra en el periodo 1759-1855 y se ocupa de presentar una breve biografía de cada viajero seguida de una descripción resumida del viaje que realizó utilizando fragmentos de textos originales.

\section{JARDINE Y TOWNSEND ENTRE LOS VIAJEROS BRITÁNICOS DEL SIGLO XVIII}

Alexander Jardine (?-1799) fue un militar ilustrado que a lo largo de su vida mantuvo una fuerte vinculación con España, llegando a dominar el español y a poseer un profundo conocimiento de las instituciones y las costumbres del país. En 1762, siendo ya oficial, es enviado a Gibraltar para participar en la defensa de la Roca, donde permanece un año — hasta la firma del Tratado de París de 1765-, periodo durante el cual visita algunos países del Mediterráneo y en el que probablemente conoce a su mujer, una gibraltareña de origen español.

En 1776 pasa a la situación de invalidez para no levantar sospechas en una nueva misión en España, cuyo objetivo era informar sobre la situación real del país y encargarse eventualmente de la organización de la intendencia en caso de guerra. Así, entre 1777 y 1779 viaja por la Península con su familia como oficial 
retirado, dedicado a elaborar informes secretos de carácter estratégico y defensivo ${ }^{1}$. Jardine entró en España por el País Vasco y Navarra, atravesó la cornisa cantábrica y llegó a La Coruña, permaneciendo cerca de un año en Galicia - lugar apenas frecuentado por los viajeros británicos- Hacia mediados de 1778 está en Lisboa, desde donde decide ir Gibraltar para luego volver de nuevo a Galicia pasando por Andalucía, La Mancha, Madrid y Castilla la Vieja.

Éste es precisamente el viaje por España que luego reflejaría en Letters from Barbarie, France, Spain, Portugal by an English officer, un libro en dos volúmenes publicado en Londres en 1788 con un éxito considerable, pues se tradujo enseguida al alemán (1790) y en Inglaterra llegó a alcanzar tres ediciones (y varias reediciones) en veinte años. Sin embargo, no se tradujo al castellano debido a sus duras críticas contra las instituciones españolas (la monarquía borbónica, el clero, la Inquisición, la Mesta, etc.) y al inoportuno momento de su publicación —un año antes de la Revolución Francesa, acontecimiento que acabaría originando una reacción involucionista del gobierno español (Pérez Berenguel, 2001, p. 45)—.

Jardine era un hombre de espíritu ilustrado y amplias inquietudes. En las cartas de España cita y demuestra conocer a autores como Smith, Montesquieu, Mirabeau, Hume, Rousseau o Helvètius, empleando algunas de sus ideas para defender sus propios planteamientos ${ }^{2}$. Por otra parte, a su regreso a Londres en 1780 encontró una efervescencia cultural y política animada por los dissenters ${ }^{3}$, y probablemente participó en la Revolution Society, una de las muchas sociedades nacidas por entonces para estimular y favorecer la reforma política, a cuyas reu-

${ }^{1}$ En 1779 la firma del Tratado Secreto de Aranjuez entre España y Francia supuso la reanudación de las hostilidades con Inglaterra, lo que obligó a Jardine, a la sazón espía extranjero, a una salida precipitada de la Península.

2 El espíritu de las Leyes de Montesquieu y La Riqueza de las Naciones de Smith son las obras a las que más referencias directas e indirectas aparecen en la obra de Jardine. En ella se hace referencia directa a Montesquieu en relación a la división de poderes (Jardine, 2001 [1788], pp. 245, 344, 356) y a sus ideas sobre el clima y la civilización, y a Smith en relación a la idea de libertad económica y comercial (Jardine, 2001 [1788], pp. 216, 220 y 370). También se observa la influencia de Smith en Jardine (2001 [1788]) en cuestiones tales como la crítica al «bullionismo» (pp. 194, 200, 245), la reivindicación de un entrono de libertad y seguridad promovido por un Estado reducido (pp. 194, 321), la importancia de la búsqueda de la mejora de la propia condición como motivación económica básica (pp. 220, 347-8, 353, 365, 382-385), la exposición de las virtudes de la competencia (p. 207), o la necesidad de aplicar la división del trabajo a una administración pública descentralizada (pp. 366-367, 166-167, 320). Por otra parte, la opinión de Jardine sobre el carácter nacional coincide con la que expone Hume en su obra De los caracteres nacionales, donde considera que son las causas morales - y no el clima - las principales responsables de la creación de carácter.

${ }^{3}$ Inicialmente se trató de un movimiento de disidencia relacionado con la crítica a algunas doctrinas de la iglesia anglicana, pero luego se extendió a un planteamiento reformista de la vida política y parlamentaria, partiendo de los conceptos de derechos sagrados, mayor felicidad para el mayor número, y voz y voto para todos los contribuyentes en los asuntos de gobierno (Pérez Berenguel, 2001, p. 46). 
niones asistía Godwin con asiduidad. Lo que sí se sabe con certeza es que Jardine fue miembro y redactor inicial de los estatutos de la Philomathian Society, un club de discusión filosófica del que también formaba parte Godwin ${ }^{4}$.

En 1793 Jardine es nombrado cónsul británico en La Coruña, cargo que ostenta hasta 1796 y que estaba muy ligado a los asuntos comerciales. Será precisamente en esta época cuando conocerá a Jovellanos, carteándose con él durante casi tres años (correspondencia que no se ha conservado) y enviándole su libro de viajes, que el ilustrado español juzgará muy favorablemente en sus Diarios ${ }^{5}$. Sin embargo, en octubre de 1796 la labor de Jardine como cónsul se verá bruscamente interrumpida: tras la firma de un nuevo tratado con Francia, España declara la guerra a Gran Bretaña y Jardine es conminado a abandonar el país de inmediato, pero su estado es delicado e intenta retrasar la partida. Finalmente, en 1799 tendrá que marchar precipitadamente hacia Portugal en condiciones lamentables, donde morirá el 16 de julio.

Joseph Townsend (1739-1816) fue quizá el viajero británico de más amplia formación y mayor capacidad analítica de cuantos visitaron España en el siglo XVIII. Se educó en la cultura clásica en Cambridge, obteniendo el grado de Master of Arts en 1765, y a continuación viajó a Edimburgo para estudiar medicina. Previamente, en 1763, había tomado las sagradas órdenes, aunque el tema religioso no iba a acaparar su atención en el futuro (Robertson, 1988a, p. 134).

Su curiosidad le llevó a viajar a Irlanda en 1769 y posteriormente a Francia, Holanda y Flandes, donde tuvo oportunidad de conocer a distinguidos hombres de ciencia. Por otra parte, sus amplias inquietudes intelectuales le hicieron interesarse vivamente por la agronomía, la conquiliología ${ }^{6}$, la paleontología y la geología. Pero además, escribió sobre temas tan diversos como el despotismo y la libertad -Free thoughts on despotic and free governments (1781)_, la medicina - The Physician's Vade-Mecum (1781), A Guide to Health (1795)_, o la controvertida cuestión de las leyes para el alivio de los pobres -Observations on various plans for the relief of the poor (1778), A Dissertation on the Poor Laws (1786)-. Precisamente sus reflexiones sobre este último asunto le hacen ser considerado uno de los predecesores de Malthus. En concreto, Townsend (1786) intentó mos-

4 Pérez Berenguel (2001, pp. 49-56). Según este autor, «Jardine no compartía con Godwin algunos de sus planteamientos más utópicos ni la confianza absoluta de éste en la benevolencia humana, pero esto no era óbice para que muchas de sus ideas hubieran sido ya planteadas en parecidos términos en su libro. Éstas eran la importancia de la educación, la desaparición de los ejércitos profesionales y su conversión en una milicia permanente, la abolición del colonialismo, la apertura del comercio y la necesidad de una graduación de las reformas» (pp. 51-52). En 1793, el intento de Jardine de hacer que Godwin actuase como mediador entre Gran Bretaña y la Francia revolucionaria provocaría una dura reacción de éste último contra el primero.

5 Véase, por ejemplo, Jovellanos (1953, p. 388), entrada 13/2/1794.

${ }^{6}$ El estudio de los moluscos y, particularmente, de sus conchas. 
trar lo indeseable de unas Leyes de Pobres que animaban a las parejas a tener demasiada descendencia, agravando así la miseria que pretendían aliviar ${ }^{7}$. Respecto a los temas económicos en general, Townsend se mostró, al igual que Jardine, como un buen conocedor de la obra de Adam Smith ${ }^{8}$.

En 1786, tras la muerte de su primera esposa, emprende un largo viaje por España que durará un año y cuatro meses, y fruto de sus impresiones publicará en Londres en 1791 un libro titulado A journey through Spain in the years 1786 and 1787; with particular attention to agriculture, manufactures, commerce, population, taxes and revenue of that country. El libro — en tres volúmenes- fue traducido al alemán el mismo año de su publicación y su segunda edición apareció en 1792. En 1809 se publicó la traducción francesa, y en 1814 salió a la venta una nueva edición en dos volúmenes. Sin embargo, hasta 1988 no vería la luz la traducción castellana ${ }^{9}$. Townsend murió en 1816 a la edad de setenta y ocho años.

\footnotetext{
7 Townsend pensaba que el único método para mejorar efectivamente las condiciones de los pobres era impedir que la población creciera en exceso alcanzándose el nivel de subsistencia. Así, diez años después de la publicación de La Riqueza de Smith, Townsend (1786, sec. VIII) mostró la indeseabilidad de las Leyes de Pobres mediante modelo de «equilibrio natural», sirviéndose del ejemplo de una isla poblada por cabras y perros. El ejemplo era el siguiente. En una exuberante isla de gran fertilidad los españoles soltaron un pequeño contingente de cabras. Con el tiempo, éstas se reprodujeron rápidamente, dando lugar a una creciente presión sobre los medios de subsistencia, hasta el punto de que la otrora idílica existencia de las cabras pasó a ser de extrema dureza: sólo los ejemplares más fuertes sobrevivían. Finalmente, la población llegó a estabilizarse. Pasado un tiempo, los piratas ingleses empezaron a utilizar la isla como base de operaciones, basando su alimentación en la caza de cabras. Entonces, con objeto de debilitar la posición de los ingleses, los españoles introdujeron perros en la isla para que se comieran a las cabras. Al principio la población de perros creció con rapidez dada la abundancia de carne. Pero las cabras — que pasaron a refugiarse en las zonas altas de las colinas - disminuyeron sensiblemente en número, de modo que la población de perros tendió también a estabilizarse. La moraleja del ejemplo es que la isla ya nunca más sería un lugar de abundancia (ni para los perros ni para las cabras), y que sólo los animales más fuertes serían capaces de sobrevivir.

8 Townsend (1988 [1791], pp. 283, 291) cita dos veces a Smith (1987 [1776]) en su libro, una en relación al precio y comercio del grano, y otra en referencia a la cuestión de la población. Pero implícitamente, como se verá más adelante, la huella de Smith parece estar siempre presente, desde el análisis de los problemas económicos y las críticas a ciertas políticas proteccionistas e intervencionistas llevadas a cabo por los borbones, hasta los remedios propuestos para mejorar la situación de la economía española. No obstante, es difícil calificar a Townsend de «smithiano convencido»: hay que tener en cuenta que Smith sintetizó un pensamiento preexistente y que muchas de sus ideas se podían encontrar ya en otros autores. Además, hay una notable diferencia en la cuestión de los pobres, pues Smith estaba a favor de los altos salarios como indicador de bienestar y estímulo a la laboriosidad y a la productividad. En este punto la visión de Townsend sobre las leyes de pobres era realmente anti-smithiana.

9 Probablemente las tormentosas relaciones hispano-británicas de finales del siglo XVIII y comienzos del XIX, dominadas por el enfrentamiento desde 1795, desaconsejaron cualquier traducción de una obra que contenía dosis de crítica importantes. Luego el libro quedó olvidado en nuestro país a pesar de los elogios de autores como Blanco White. De forma general, quizá también pudieron influir negativamente los ataques del viajero ilustrado Antonio Ponz desacreditando las obras sobre
} 
De entre todos los viajeros ingleses del siglo XVIII, el itinerario de Townsend es, con diferencia, el más completo ${ }^{10}$. Sin embargo, no visita algunos lugares que sí recorre Jardine, como Galicia, el País Vasco o Navarra, lo que remite a la idea de complementariedad entre los itinerarios de ambos viajeros que se señalaba en la introducción ${ }^{11}$. También se complementan los periodos de visita: aunque los libros de ambos se publiquen casi a la par, Jardine nos da una imagen del país a partir de impresiones recogidas entre los años 1777 y 1779, mientras que Townsend refleja la situación del país casi diez años después, pues su estancia se sitúa entre enero de 1786 y agosto de 1787 . Del mismo modo, hay complementariedad en el enfoque o aproximación a los problemas de España. Jardine, que elige la forma epistolar para presentar las impresiones de su viaje, se interesa especialmente por cuestiones económicas relacionadas con el comercio internacional y el marco institucional. Además, en vez de hacer una descripción detallada de la situación española y de las regiones que visita con cifras concretas, parte de lo que observa para reflexionar en abstracto — a veces de forma un tanto caótica — sobre temas muy diversos: las causas de la decadencia española, las posibilidades de reforma, el papel del buen gobernante, o el valor del viaje como escuela — considerando a España como un lugar donde estudiar la situación de la vieja Europa (Freixa, 1991, p. 120) — Es decir, en vez de una relación objetiva de datos y hechos, su libro es esencialmente una meditación a partir de ellos que busca hacer pensar al lector. Townsend, por el contrario, antes de permitirse cualquier análisis recoge sistemáticamente todo tipo de datos sobre las zonas que visita, mostrando su carácter de hombre científico: población, producciones, precios y jornales, actividad comercial, tributos, usos y costumbres, etc. Además, allí por donde pasa presta especial atención a los temas que más le interesan, como la estrucura geológica del territorio y la composición de los suelos, el uso de distintos tipos de maquinaria agrícola y manufacturera, las instituciones para pobres, o la situación de la atención médica. Y no sólo se contenta con lo que puede observar de forma

España de algunos viajeros extranjeros. En cualquier caso, es sintomático que ninguno de los libros escritos por los viajeros británicos que visitaron la Península en el siglo XVIII fuera traducido al castellano, aunque sí se tradujeron libros de viajes británicos realizados por diversas partes del mundo (García-Romeral, 1997, pp. 219-242).

10 Townsend entró en España por Gerona, y fue de Barcelona a Madrid pasando por Zaragoza, Guadalajara y Alcalá; de Madrid se dirigió a Asturias por León, y de allí regresó a El Escorial y Madrid pasando por Zamora, Salamanca, Ávila y Segovia. Desde Madrid se encaminó a Sevilla, atravesando La Mancha y Sierra Morena y haciendo parada en Córdoba. Luego viajó a Cádiz, Málaga, Granada, Cartagena, Alicante y Valencia, con múltiples escalas a lo largo del camino. Por fin, desde Valencia emprendió el regreso pasando de nuevo por Barcelona. Tras dejar España, y atendiendo a su afición a la geología y a los fósiles, tenía previsto un viaje a Suiza para demostrar que el relato bíblico del Diluvio Universal era estrictamente cierto. Sobre esto último, véase el artículo de Freixa (1999, p. 7).

11 Jardine, sin embargo, no visitó Cataluña, ni Aragón ni Levante, que sí recorrió Townsend. 
directa, sino que — cargado de cartas de presentación — visita a hombres de ciencia, políticos y eclesiásticos, así como fábricas e instituciones civiles y militares, recabando informaciones muy diversas ${ }^{12}$.

En definitiva, Townsend se acerca mucho más que Jardine al ideal del viaje «filosófico» o «ilustrado», en la medida en que intenta obtener y transmitir un conocimiento enciclopédico del país que sea útil a la sociedad, siguiendo las pautas marcadas por autores como el obispo Tucker o el conde de Berchtold (Guerrero, 1990, pp. 40-44) ${ }^{13}$. En efecto, el libro de viajes —que conoció un auténtico boom en el Siglo de las Luces ${ }^{14}$ _ debía educar, en el sentido de transmitir unos conocimientos sobre una determinada realidad humano-geográfica de los que pudieran derivarse enseñanzas que contribuyesen a mejorar el propio país. Ahora bien, ¿qué podía aprenderse de España, una nación decadente y atrasada que arrastraba además una imagen muy poco favorable entre los británicos desde mediados del siglo XVII ${ }^{15}$ ? ¿Por qué ir a un país periférico y aislado en el que no se habían producido avances científicos o técnicos ni innovaciones en la forma de gobierno?

12 Townsend no tenía más que unas nociones muy burdas de español cuando llegó y tuvo claras dificultades con el idioma. Parece que utilizó el francés e incluso el latín para comunicarse con los miembros de las clases dirigentes y de la aristocracia. Véase, por ejemplo, Townsend (1988 [1791], pp. 73, 81, 105, 121, 160, 182 y 407).

${ }^{13}$ Las obras en las que marcaron dichas pautas fueron J. Tucker, Instructions for travellers, Londres, 1757, y L. Berchtold, Essays to direct and extend the inquiries of patriotic travellers, Londres, 1789. Ya en 1666 la Royal Society había publicado unas instrucciones para viajeros, en las que recogía un catálogo de las preguntas que éstos debían hacerse y de las cosas que debían observar para que su viaje resultara provechoso a la colectividad, proporcionando una información lo más objetiva posible (Guerrero, 1990, pp. 33, 40-44). El ensayo de Francis Bacon (1625) «Of travel» está en los orígenes de la idea de viaje «ilustrado». En España, su reflejo más claro lo da Clavijo y Fajardo (1762, pp. 161-164): el viajero debe «observar el gobierno de los pueblos por donde pasa y enterarse de los varios sistemas de legislación de que proviene la discrepancia de las naciones [...] examinando con igual cuidado las artes y ciencias [...] Un hombre que viaja de esta manera puede ser de grande utilidad a la República [...] compara lo que ha visto fuera con lo que ha visto en su país; ve lo que falta y lo que sobra; toma de cada pueblo lo que le parece más digno de ser imitado».

${ }_{14}$ En Francia es donde más libros de viajes se imprimieron y leyeron, mientras que en Inglaterra los datos aportados por los viajeros habían empezado a sistematizarse ya en el siglo XVII. En España el género de viajes también tuvo importancia, como lo demuestra el considerable número de libros publicados sobre el tema y la presencia de este tipo de literatura entre las lecturas habituales de muchos de los ilustrados (véase García-Romeral, 1997, pp. 9-11).

15 Como ha destacado Shaw (1981) en un amplio estudio, los viajeros británicos de la segunda mitad del siglo XVII, como Francis Willoughby, Veryard Ellis o William Bromley, ofrecieron una imagen de España muy negativa: un país despoblado, sin cultivo ni manufactura, con su comercio en manos extranjeras, unas comunicaciones lamentables, y una población holgazana y supersticiosa dominada por la Iglesia. Esta imagen negra fue precisamente la que —en opinión de Freixa (1994)_ recogieron y repitieron a modo de estereotipo las grandes colecciones geográficas e históricas publicadas en Gran Bretaña en el siglo XVIII. 
España, efectivamente, había quedado al margen del Grand Tour que realizaban los ciudadanos británicos de las clases más acomodadas, y especialmente los hijos de la nobleza como parte esencial de su educación. El Tour, que sin duda fomentó la discusión, el intercambio y la difusión de ideas y corrientes artísticas ${ }^{16}$, se centraba en el siglo XVIII en Francia, Italia, los Países Bajos y algunas zonas de la Europa central, pero dejaba completamente de lado a España, un país culturalmente desprestigiado del que — en opinión de Voltaire — se sabía tan poco como de África, pero que no valía la pena conocer ${ }^{17}$. Sin embargo, quizá fuera precisamente ese desconocimiento y ese alejamiento cultural, unidos a la dificultad del propio viaje por la Península, lo que hizo que en el último tercio del siglo XVIII España volviera a despertar cierto interés ${ }^{18}$. De este modo, ya fuera por el simple afán de aventura más allá de los caminos trillados —aunque lejos aún de la búsqueda romántica del pintoresquismo_-, o ya fuera por la mera curiosidad intelectual y por el deseo de ofrecer una versión propia de la realidad del país - llenando así el vacío bibliográfico existente con un estudio objetivo y científico-, lo cierto es que algunos viajeros volvieron a considerar España como destino apetecible (Freixa, 1991, p. 95). Esto último es probablemente lo que sucedió con Townsend, mientras que Jardine — como se ha visto — vino obligado por su profesión militar, aunque animado por el reto que suponía un viaje de tales características.

La enseñanza más clara que cabía obtener de España era la de sus errores. Una nación otrora poderosa había caído hacía tiempo en una situación de postración, seguramente debido a su mal gobierno: «Aquí podemos estudiar el mal gobierno y trazar toda la cadena de sus efectos perniciosos [...] Podemos ver cómo un principio falso genera innumerables daños que no son previstos por la sabiduría humana, y cómo un abuso abre la puerta a otros muchos» (Jardine, 2001 [1788], pp. 251-252). Era por tanto interesante analizar las causas de la decadencia del país, y aprender cómo no debían hacerse las cosas y qué peligros podían derivar-

16 Véase Enciso (1987).

17 Carta de Voltaire al viajero inglés Sherlock en 1766, citada en Guerrero (1990, p. 15). En el mismo sentido se expresaba John Fielding, editor de The polite traveller and the British navigator, una colección textos en cuatro volúmenes publicada en Londres en 1783 (vol. II, p. 92): «Nada excepto la necesidad puede inducir a alguien a viajar por España: debe ser idiota si hace el tour de este país por mera curiosidad, a menos que pretenda publicar las memorias de la extravagancia de la naturaleza humana. En este caso, no puede hacer mejor, porque en todos los sitios encontrará orgullo, bajeza, pobreza, ignorancia, fanatismo, superstición y ridículas ceremonias» (citado en Freixa, 1991, p. 72).

${ }^{18}$ El mayor número de viajeros británicos se concentró, con diferencia, entre 1770 y 1779, año en que España, aliada de Francia, decide apoyar a los rebeldes en la Guerra de la Independencia Americana. Luego, desde los tratados de París y Versalles (1783) hasta el pacto hispano-francés de 1795 y la posterior declaración de guerra a Inglaterra en 1796, el número de viajeros descendió muy significativamente. 
se del excesivo intervencionismo y de la falta de libertades. Además, el lector británico también podía aprender a valorar mejor los logros conseguidos en su propio país en términos de instituciones políticas y organización económica, logros que sin duda habían situado a Gran Bretaña en una posición privilegiada, de superioridad, en el contexto europeo.

Pero junto este objetivo ilustrado de los viajes de Jardine y Townsend que acaba de reseñarse, centrado en intentar educar a la población de procedencia, hay que contemplar también otro objetivo adicional menos ilustrado y explícito, que era el de proporcionar una información económica que podía llegar a ser crucial en una situación de guerra entre España e Inglaterra. Hay que tener en cuenta que durante todo el siglo XVIII existió una fuerte rivalidad económica, política y militar entre las principales potencias europeas. En este contexto, tal como demostraron los hechos, la guerra estaba lejos de ser sólo una posibilidad remota, y todo conocimiento del potencial enemigo resultaba relevante, especialmente en el terreno económico.

\section{LA IMAGEN DE LA ECONOMÍA ESPAÑOLA EN LA ÉPOCA DE CARLOS III SEGÚN JARDINE Y TOWNSEND}

\subsection{Una mirada condicionada pero valiosa}

Townsend y Jardine dan una imagen de la economía y la sociedad españolas de la segunda mitad del setecientos bastante menos favorable que la que generalmente manejamos hoy ${ }^{19}$. En efecto, si se tiene en cuenta una perspectiva de largo plazo y se considera cuál era la situación económica en el siglo XVII ${ }^{20}$, el reinado de Carlos III y su reformismo ilustrado se han de asociar inequívocamente a la idea de recuperación y mejora. Sin embargo, estos dos viajeros ingleses —como el resto de sus compatriotas que nos visitaron - partieron de su propia realidad económica, política, social y cultural a la hora de valorar lo que veían. Es decir,

19 Véase por ejemplo el amplio análisis de Anes (2000) de la economía española en el siglo XVIII. Más concretamente, para el reinado de Carlos III, Vicent Llombart (1992, pp. 352-360) hace un balance bastante positivo de la política económica del periodo.

${ }^{20}$ La idea de un siglo XVII depresivo, que fue ampliamente difundida en su día por los artibitristas — véase Perdices (1996) — , se ha venido sosteniendo tradicionalmente por los historiadores con diversos matices. Anes, sin embargo, la ha puesto en cuestión. En concreto, en el caso del agro castellano, Anes (1978, p. 108) cree que hubo más bien una serie de lentos ajustes y readaptaciones para armonizar la producción de subsistencias y el número de habitantes. Sin embargo, muchos historiadores no están de acuerdo con esta tesis. Llopis (1986), por ejemplo, defiende la existencia de una intensa depresión agraria en Castilla en la primera mitad del Seiscientos, y Kamen mantiene la idea de un siglo depresivo con algunos signos de recuperación durante el reinado de Carlos II (Kamen, 1981, pp. 107 y ss.). 
compararon lo observado con la realidad de un país - el suyo- en plena efervescencia cultural y científica, que disfrutaba de altas cotas de libertad política y tolerancia religiosa, que poseía un sistema de gobierno en el que el monarca estaba sujeto al control del Parlamento, y que desarrollaba una agricultura de vanguardia, una vasta actividad comercial y una manufactura pujante en un marco cada vez más liberalizado y competitivo ${ }^{21}$.

Por tanto, el primer elemento que condicionó la mirada de Jardine y Townsend fue la realidad de su propio país, que les sirvió de punto de referencia. Pero además, ambos son dos firmes partidarios del liberalismo económico, de manera que adoptan una óptica muy concreta al aproximarse al análisis de la economía española, la cual les hará mostrarse muy críticos con algunas prácticas mercantilistas aún vigentes entonces España. De hecho, según Guerrero (1990, p. 302), a través de las páginas de los libros sobre sus respectivos viajes a la Península se puede asistir a la penetración, en un nivel teórico, de las ideas liberales entre los ingleses de la época.

Por otra parte, los viejos clichés sobre España arrojaban una imagen muy negativa del país ${ }^{22}$. Como se ha visto en el apartado anterior, en gran medida habían sido acuñados a partir de los escritos de los viajeros británicos que visitaron la Península en la segunda mitad del siglo XVII, y luego se trasladaron de forma acrítica a las enciclopedias y a las colecciones geográficas británicas del setecientos. Es cierto que dichos clichés se acabarían revisando precisamente gracias a las nuevas impresiones que transmitieron en sus textos los viajeros del último tercio del siglo XVIII como Townsend o Jardine, pero fueron sin duda un tercer elemento que mediatizó inicialmente su forma de «percibir» el país.

$\mathrm{Si}$ a los tres elementos anteriores unimos la dificultad que supone captar con profundidad la realidad compleja del lugar que se visita, se completa el cuadro de condicionantes. Dicha dificultad se relaciona, por ejemplo, con la premura del viaje, el desconocimiento de la lengua —en el caso de Townsend-, o las reservas de los españoles en el trato con los extranjeros — particularmente respecto a ciertos temas delicados dada la presencia de la Inquisición.

Sin embargo, si bien todos estos aspectos mediatizaron sin duda la imagen de España ofrecida por ambos viajeros, no le restan valor. Por un lado, la mirada informada de un visitante extranjero que estaba al tanto de los avances de las artes y las ciencias y que ya había visitado otros países, como era el caso tanto de

${ }^{21}$ A veces incluso, al plantear algunas ideas un tanto utópicas sobre riegos, canales y mejoras en cultivos, ambos viajeros parecen dejarse llevar también por la realidad geográfico-climática de su propio país de origen, que era bien diferente a la española, caracterizada por una difícil orografía y un clima mediterráneo de precipitaciones escasas e irregulares en buena parte del territorio.

22 Batllori (1987) transmite bien hasta qué punto la literatura de viajes del setecientos sobre España repitió viejos lugares comunes. Ello da especial valor a los libros de Jardine y Townsend por sustraerse a tal tendencia. 
Townsend como de Jardine, tiende a centrarse en los grandes problemas sin perderse en detalles irrelevantes; además tiene la ventaja de reflejar la impresión que causa lo nuevo y lo diferente en alguien que se acerca a una realidad desde fuera, sin los velos de lo acostumbrado. Por otra parte, lo que hoy interesa no son tanto los datos concretos aportados por los viajeros para dar una apariencia de imparcialidad y rigor a su relato — que suelen ser de segunda mano, tomados de aquí y de allá, y a veces de dudosa fiabilidad-, sino las anécdotas que transcriben y sobre todo las opiniones que formulan y los análisis que realizan, pues reflejan la difusión de unas determinadas concepciones económicas, revelan estereotipos culturales y convenciones sociales, y nos informan sobre los intereses de una sociedad concreta — la británica - a la hora de hacerse preguntas sobre otras naciones.

\subsection{Un país aún en decadencia y con pocas posibilidades de despegue}

Los libros de Jardine y Townsend sobre España transmiten la idea de una persistente situación de decadencia general en un país que en su día había llegado a ser primera potencia europea. Es cierto que Jardine se muestra más crítico que Townsend, pero ambos coinciden en el diagnóstico básico.

Dicha situación de decadencia — como se verá más tarde — la observaban reflejada en el lamentable estado de las infraestructuras de transporte, en la despoblación del interior ${ }^{23}$, en la situación de atraso de la agricultura, la manufactura y el comercio, e incluso en la estructura social. Pero la causa última de la decadencia era para ambos viajeros política, y — como ya se apuntó en el segundo apartado- derivaba esencialmente del mal gobierno y de la falta de libertades. Tras un periodo de esplendor representado por los Reyes Católicos, un gobierno despótico y arbitrario se había impuesto con la llegada de los Habsburgo al trono, acabando con las libertades tradicionales que encontraban su máxima expresión en las Cortes. Así, la derrota de los comuneros marcaría simbólicamente el inicio de la decadencia. La intolerancia religiosa, una política exterior agresiva, o un

${ }^{23}$ Según Jardine (2001 [1788], p. 405), la población española era «obviamente muy escasa, especialmente en las regiones centrales». Asimismo, era «probable que el país (hubiera estado) más poblado en épocas anteriores». Townsend, por su parte, reseña varias veces a lo largo de su viaje la desolación que encuentra en las zonas del interior y afirma que «todos coinciden en señalar que antiguamente España estaba mejor poblada que en la actualidad», para acto seguido apuntar las posibles razones del despoblamiento (Townsend, 1988 [1791], pp. 239-249). Hoy, sin embargo, sabemos que a lo largo del siglo XVIII el crecimiento de la población española -aunque con variaciones regionales - fue continuo, pasando de 7,6 millones en 1717 a 10,5 millones en 1797 (Lynch, 2004, p. 176). Con todo, es posible que en determinadas zonas del interior pudiera apreciarse un fenómeno de despoblación, como en muchas aldeas de Castilla la Vieja (Domínguez Ortiz, 1981, p. 180). 
fuerte intervencionismo que no potenciaba las actividades económicas habían guiado la política de los Austrias. Sin embargo, el despotismo borbónico, actuando sin controles ni contrapesos de ningún tipo, no supuso una mejora real, en la medida en que continuó en la línea de abortar cualquier manifestación de libertad política, económica o religiosa, sin promover verdaderamente el desarrollo del país ${ }^{24}$.

Las manifestaciones del mal gobierno, ejercido de forma absoluta, quedaban patentes en múltiples ejemplos. De hecho, prácticamente no había un solo aspecto de las políticas públicas que escapase a la crítica de los viajeros. En primer lugar, atacaban duramente el aparato tributario. Para Townsend —que hacía una detallada descripción de los impuestos españoles de la época ${ }^{25}$ — «ningún país (había) creado nunca un sistema de finanzas tan desastroso o más hostil a la industria y al comercio» (Townsend, 1988 [1791], p. 242), destacando especialmente por su carácter dañino la alcabala y los millones ${ }^{26}$. Precisamente, la exención de estos impuestos de la que disfrutaba Cataluña — donde se había instaurado a cambio una tasa del 10 por cien sobre todas las rentas- hacía que su industria, libre de tales «insensatas restricciones», se viera favorecida (Townsend, 1988 [1791], p. 421). Por su parte, Jardine definía el sistema fiscal español como «una colección de abusos fundados en la ignorancia (de los verdaderos principios de la renta nacional y la prosperidad) y en la opresión» (Jardine, 2001 [1788], pp. 239-240).

En lo referente a la política de infraestructuras ${ }^{27} \operatorname{los}$ viajeros criticaban la falta de realismo de los planes de obras públicas, que de este modo nunca se llevaban plenamente a la práctica. Townsend, por ejemplo, se refiere al Canal de Aragón y al de Castilla, destacando lo ambicioso no sólo de su trazado, sino sobre todo de su hechura ${ }^{28}$. Al comparar tan grandiosos proyectos con los estrechos pero eficaces canales ingleses, concluía que «estos canales tan modestos no satisfarían la ambición de un español, pues no coinciden con sus ideas de grandeza»

${ }^{24}$ Townsend (1988 [1791], pp. 127-129) y Jardine (2001 [1788], pp. 351-356; 409-410). Véase también Jardine (2001 [1788], pp. 195; 223; 226-228; 375).

25 Tonwsend (1988 [1791], pp. 216-224).

${ }^{26}$ La alcabala (y sus cientos) era un impuesto que gravaba con el 14 por cien las materias primas y las mercancías manufacturadas cada vez que cambiaban de manos, y se calculaba sobre el precio de venta, que, «en consecuencia, crecía constantemente». Los millones gravaban las provisiones, «por lo que (tendían) a aumentar el costo de la mano de obra» (Townsend, 1988 [1791], p. 242). En realidad, en el caso de la alcabala y los cientos la estimación de las cantidades cobradas y la recaudación de las mismas era bastante más complicada de lo que Townsend parece suponer.

27 Sobre el lamentable estado de las infraestructuras de transporte véanse, por ejemplo, las manifestaciones de Townsend (1998 [1791], pp. 52, 98) o de Jardine (2001 [1788], p. 327).

${ }^{28}$ Townsend (1988 [1791], pp. 90-91; 145-147). Townsend sabía bien de lo que hablaba, pues fue uno de los principales promotores del canal Kennet y Avon en Inglaterra en calidad de gran accionista (Robertson, 1988b, p. 14). 
(Townsend, 1988 [1791], p. 91). En el mismo sentido se expresaba Jardine, que tras revisar los planes existentes de nuevos canales destacaba su «apariencia excesiva de «globos» y de engaño, al ser tan irrealizables e inadecuados tanto en los medios como en los fines» (Jardine, 2001 [1788], p. 334). Lo mismo ocurría con los caminos, dada la tendencia a hacerlos mucho mejores y más caros de lo necesario: «Este gobierno lleva veinte o treinta años planeando caminos, comenzando $\mathrm{y}$ abandonando un proyecto irrealizable tras otro [...] quieren que todo sea a la vez grande y suntuoso, y por eso fracasan en todo y no acaban nada ${ }^{29}$. En realidad, unas obras tan grandiosas «exigirían un nivel de población y de comercio interior mucho mayor» (Jardine, 2001 [1788], pp. 318 y 320).

El ámbito de la educación presentaba también múltiples deficiencias. Por un lado, era «tan elevado el número de analfabetos» que el oficio de escribiente suponía ingresos seguros (Townsend, 1988 [1791], p. 307). Por otro lado, pocas personas parecían interesadas por la ciencia y apenas se leían libros ${ }^{30}$ (Townsend, 1988 [1791], p. 214). Este hecho se combinaba con una escasa afición a la música y al teatro, una completa falta de crítica intelectual, y un claro atraso «en la ciencia útil» ${ }^{31}$. Así, en los anticuados programas de las universidades, donde «nada (podía) suplantar a Aristóteles y a los supersticiosos padres y doctores de la Iglesia [...] aún (estaban) prohibidos Newton y la filosofía moderna» (Jardine, 2001 [1788], p. 328) ${ }^{32}$. No era de extrañar entonces que Townsend, un hombre con amplios conocimientos en geología, botánica y medicina, concluyese con rotundidad que «la ciencia y la práctica de la medicina (alcanzaban) un nivel ínfimo en España» (Townsend, 1988 [1791], p. 171).

Este atraso científico se relacionaba directamente con la existencia de la Inquisición: «Es probable que la tiranía inquisitorial impida el acceso a la cadena completa del conocimiento útil y la libertad de investigación durante mucho tiempo. Allí donde se tiene tanto a los filósofos como a los libros como algo peligroso, poca o ninguna será la influencia que éstos puedan ejercer» ${ }^{33}$ (Jardine, 2001

${ }^{29}$ En el mismo sentido, véase Townsend (1988 [1791], p. 198): si la ambición de los españoles «fuera más moderada ya habrían abierto una comunicación entre sus principales ciudades, y muchos de los productos que ahora se pierden habrían encontrado mercado».

30 Jardine, que también destacaba el bajo nivel de lectura (Jardine, 2001 [1788], p. 217), se sorprendía sin embargo de la corrección general en el uso del lenguaje hablado, «incluso por parte de los campesinos», lo que contrastaba con lo que sucedía en Gran Bretaña (Jardine, 2001 [1788], p. 277).

${ }^{31}$ Jardine (2001 [1788], pp. 217; 271); Townsend (1988 [1791], p. 214).

32 Véanse en el mismo sentido las afirmaciones de Townsend (1988 [1791], p. 186) al referirse a la universidad de Salamanca. En referencia a la universidad española en su conjunto afirma: «La anticuada filosofía de Aristóteles mantiene aquí su imperio sin rival» (Townsend, 1988 [1791], p. 129).

${ }^{33}$ La influencia de la Inquisición en el desarrollo científico debe matizarse según campos de saber. Mestre (1976, p. 171), por ejemplo, considera que desde finales del siglo XVII hubo concien- 
[1788], p. 212). Los intelectuales también eran víctimas de la intolerancia religiosa — «el temor que despierta la Inquisición impide que los hombres de letras confíen en trasladar sus ideas al papel» (Jardine, 2001 [1788], p. 219)—y el caso de Olavide era citado en este sentido por Townsend y Jardine ${ }^{34}$. Aunque ambos viajeros reconocían que la autoridad de la Inquisición había menguado, aún la consideraban importante ${ }^{35}$. Por otra parte, el excesivo poder de la Iglesia católica se dejaba notar en las múltiples manifestaciones de extremado fervor religioso (procesiones, flagelaciones penitenciales, etc.), que los viajeros veían como muestras de superstición y fanatismo del pueblo, pero paradójicamente no tenía efecto alguno en la moralidad del país, donde se observaban costumbres muy relajadas. Así, el reverendo Townsend hablaba de la «depravación moral» del clero español, pues «en las grandes ciudades los canónigos de las catedrales (constituían) los cortejos más importantes» de las mujeres casadas, al tiempo que «buena parte del clero de las parroquias (era) cabeza de familia» (Townsend, 1988 [1791], p. 213). Por último, tanto Townsend como Jardine se lamentaban repetidamente de la enorme cantidad de riqueza inmovilizada en manos de la Iglesia:

«No hay pluma que pueda estimar [...] cuál habría sido el valor de lo generado si en vez de encerrarse e inutilizarse (la riqueza de la Iglesia) hubiera sido empleada para facilitar las comunicaciones [...], para mejorar el suelo mediante drenajes, plantaciones y regadíos, o para establecer, incentivándolas por medio de primas y préstamos, industrias útiles y adecuadas al talento de la población y a la naturaleza del territorio. Si toda esta riqueza se hubiera canalizado hacia un fin útil, ¡qué distinta sería España!» (Townsend, 1988 [1791], p. 125).

La Iglesia también es objeto de crítica en relación a la política de pobres. Según Jardine (2001 [1788], p. 380), la caridad mal entendida mantenía a los pobres «en la holgazanería y (fomentaba) el oficio de la mendicidad». Por su parte, Townsend, que había tratado ampliamente el tema de las leyes de pobres

cia de la revolución científica que se estaba produciendo en Europa y un deliberado interés pos seguir sus adelantos, y que la Inquisición puso claros reparos a los estudios matemáticos y astronómicos, pero se mostró relativamente tolerante con las ciencias físico-químicas y los adelantos médicos.

34 Townsend (1988 [1791], p. 276); Jardine (2001 [1788], p. 270).

35 «Creo que incluso los inquisidores se han humanizado a medida que las luces se han esparcido por Europa. Sin embargo, los hechos [...] nos indican que debemos seguir lamentando que los tribunales sigan teniendo el suficiente imperio» (Townsend, 1988 [1791], p. 425). El propio Townsend visita varias veces a un inquisidor en Granada «culto y muy humanitario», que le recibe muy amablemente a pesar de ser él «un pastor inglés, un maestro de la herejía». Asimismo visita el llamado quemadero, casi ya en ruinas, pero donde sólo ocho años antes se había quemado «a dos judíos y a un turco» (Townsend, 1988 [1791], p. 338). 
inglesas antes de su viaje a España y visitó prácticamente todas las instituciones civiles y religiosas dedicadas a los pobres que encontró a su paso, consideraba asimismo que el número de mendigos «(crecía) en proporción directa a las medidas que se toman para aliviar sus males». La caridad no sólo fomentaba la indolencia y constituía una rémora para la industria, sino que alimentaba la miseria al favorecer un rápido crecimiento demográfico, dado que «los hombres se multiplican en proporción al alimento disponible» ${ }^{36}$ (Townsend, 1988 [1791], p. 291). Incluso los hospicios que intentaban enseñar un oficio a los pobres — como el de Oviedo o el de Cádiz- eran duramente criticados, pues las condiciones no eran lo suficientemente duras con ellos como para inducirles realmente al trabajo:

«El pobre encuentra aquí el mismo incentivo para trabajar que encontraría para cavar un pozo si dispusiera de una fuente. [...] Corregir a los holgazanes y a los despilfarradores y confinarlos en ciertas instituciones hasta que hayan aprendido a ser sobrios y trabajadores es justo y prudente; pero el que en estos establecimientos se les proporcione comida, ropa y alojamiento mejores que los que disfrutan las personas sobrias y diligentes no concuerda con ningún principio de equidad ni demuestra sensatez» ${ }^{37}$ (Townsend, 1988 [1791], pp. 161; 292).

Además, los productos manufacturados en los hospicios a menudo hacían una competencia desleal a la industria local, contribuyendo a su desaparición. Así, el arzobispo de Toledo, que subsidiaba los talleres de seda del hospicio de dicha ciudad, estaba minando esta manufactura otrora pujante: «amparado en la fuerza de su capital (el arzobispo) ha elevado el precio de la mano de obra y de la materia prima, al tiempo que ha saturado el mercado y obligado a bajar los precios tanto que los fabricantes ahora sólo pueden emplear a dos o tres (obreros)» (Townsend, 1988 [1791], p. 123).

${ }^{36}$ «Si puede satisfacer sus necesidades, la población verá enseguida duplicar su número, y así ad infinitum, lo que no concuerda con la realidad. En caso de que fuera posible desterrar el hambre y satisfacer la necesidad de comer en detrimento de otra, no quedaría otra forma de limitar la población que la de controlar el número de matrimonios. No hay esfuerzo humano que pueda deshacer este dilema, y nunca encontrarán los hombres un método más natural y eficaz que dejar que un apetito regule al otro» (Townsend, 1988 [1791], p. 292).

${ }^{37}$ Es importante tener en cuenta que para Townsend el pobre generalmente lo era por méritos propios: «Muchos miembros de las clases bajas carecen de sentimientos generosos y [...] a la mayoría de ellos su propia indolencia les ha abocado a la miseria y a la pobreza» (Townsend, 1988 [1791], p. 290). Además, en la línea de Mandeville (1997 [1729], pp. 265-6), Townsend opinaba que a los niños de los pobres no se les debía dar educación con fondos públicos, sino que debían ser puestos a trabajar cuanto antes: «la enseñanza que reciben (en las escuelas públicas) no les suele hacer fuertes, que nunca han sido buenos criados y que al salir nunca han estado capacitados para hacerse cargo de una familia, al contrario de lo que ocurre a los que se han criado en chozas y desde su infancia ha aprendido a pechar con toda clase de trabajos» (Townsend, 1988 [1791], p. 290). 
La nobleza era seriamente cuestionada por no desempeñar función alguna en la sociedad española: «lleva en su mayor parte una vida perezosa, y que deberíamos llamar inútil y quizá viciosa, que se reparte entre el carruaje, las cartas, la iglesia y la intriga» (Jardine, 2001 [1788], p. 288) ${ }^{38}$. En primer lugar, los nobles preferían la vida urbana y no se interesaban lo más mínimo por la buena administración de sus propiedades rústicas ni por la introducción de mejoras agrarias:

«En toda España no recuerdo haber visto una sola residencia campestre como las que tanto abundan por toda Inglaterra. La gran nobleza rodea al soberano y se siente atraída por la corte, mientras que los nobles de categoría o fortuna inferior se congregan en Madrid o [...] en las grandes ciudades de las provincias» ${ }^{39}$.

En segundo lugar, la gran aristocracia, que no se preocupaba de pulir su educación ni de viajar al extranjero para conocer mundo, tampoco asumía puestos de responsabilidad en el gobierno: «En las clases altas todo está adormecido. Satisfechos con las riquezas y los honores heredados, los nobles no viven más que para el placer [...] Los principales ministros se ven en dificultades para encontrar hombres capacitados para desempeñar los cargos más corrientes» (Townsend, 1988 [1791], p. 251) ${ }^{40}$. Por último, los nobles, amparados en sus grandes privilegios hereditarios, mostraban claros perjuicios contra el comercio, que se complementaban con frecuentes muestras de desprecio por el dinero ${ }^{41}$.

La política comercial es otro ámbito que sólo merece críticas por parte de ambos viajeros, partidarios de un librecambio de inspiración smithiana, de modo que cada país cultive y produzca «lo más adecuado a su situación geográfica, su suelo, su clima

38 Según Jardine (2001 [1788], pp. 177-8) la excepción que confirmaría la regla sería el conde de Peñaflorida, elogiado como caso extraordinario por el viajero inglés. Sin embargo, según muestra Astigarraga (2003, pp. 23-74), en el País Vasco existía una nobleza activa y cultivada, de la que Peñaflorida era un representante destacado — pero no único- como impulsor principal de la Sociedad Bascongada de Amigos del País. Para Jardine (2001 [1788], p. 329), el resto de las Sociedades promovidas por Campomanes a imitación de la Bascongada no habían surtido el efecto esperado en el fomento de las artes y el comercio, balance que luego se ha visto confirmado por algunos historiadores (Carande, 1976, pp. 178-181; Herr, 1979, p. 134). De hecho, ya incluso en 1786 - como señala Anes (1981, p. 39) — el propio gobierno trató de averiguar las causas de la relativa decadencia de estas instituciones. Con todo, cabe concluir que «en su conjunto la experiencia, a pesar de todas sus obvias limitaciones [...], tuvo un alcance notable» (Llombart y Astigarraga, 2000, p. 698).

39 Townsend (1988 [1791], p. 96). Ver también la p. 215.

${ }^{40}$ Véase también en este sentido Jardine (2001 [1788], pp. 288, 290-292). Townsend (1988 [1791], p. 251) añade: «Para un inglés puede resultar sorprendente comprobar que todos los puestos importantes están ocupados por hombres que han salido de los estratos más bajos, [...](cuando) en Inglaterra ocurre exactamente lo contrario».

${ }^{41}$ Véase Tonwsend (1988 [1791], pp. 336; 193). Jardine (2001 [1788], p. 195) habla directamente de «orgullo», «indolencia»e «incompetencia para los negocios» en las clases superiores. 
y la habilidad de sus habitantes», consiguiendo lo demás por intercambio (Townsend, 1988 [1791], p. 341). El fuerte proteccionismo basado en prohibiciones, reglamentaciones y altos aranceles, al margen de restringir absurdamente el comercio, no evitaba que los productos ingleses llegasen a España a través del contrabando, pues éste ofrecía grandes oportunidades de enriquecimiento: «siempre que la gente tenga razones tan poderosas para violar las leyes no habrá gobierno alguno, por mucho que se esfuerce y por muy duras que sean las penas, [...] capaz de mantener el orden público» ${ }^{42}$. En concreto, Jardine (2001 [1788], p. 370) citaba directamente a Smith para exponer los efectos negativos de los elevados aranceles, subrayando especialmente el problema de la formación de grupos de interés ${ }^{43}$. También eran claro objeto de condena las compañías privilegiadas — como la Compañía de Filipinas—, dado que suponían un perjuicio para «los ciudadanos en general» y para las provincias «sometidas a estos monopolios» ${ }^{44}$. Además, para Townsend resultaba contradictorio que se estuviera intentando liberalizar poco a poco el comercio en el interior del Imperio ${ }^{45} \mathrm{y}$ al mismo tiempo se crearan este tipo de compañías. Por otra parte, la excesiva focalización del comercio colonial español en los metales preciosos había «desviado la atención de la gente [...] de las artes útiles y la industria a la propensión al riesgo y la aventura», pues la posibilidad de enriquecimiento fácil hacía que se hubieran abandonado los caminos progresivos y laboriosos de la obtención de la verdadera riqueza ${ }^{46}$.

42 Townsend (1988 [1791], p. 263); véase también Jardine (2001 [1788], p. 184).

43 «Una vez que se establece cualquier abuso o imposición sobre la base del interés de cualquier grupo influyente de personas, éste resulta entonces casi inamovible» (Jardine, 2001 [1788], p. 248; véase también p. 300). Townsend (1988 [1791], pp. 399-400) citaba como ejemplo de las contraproducentes consecuencias de las regulaciones de tipo colbertista el caso de la prohibición de la exportación de seda en España, que supuestamente pretendía mantener abastecido el mercado nacional a precios asequibles: «Si se permitiera la libre exportación de la seda su precio subiría, lo que a su vez limitaría naturalmente su salida del país, y el productor entonces encontraría un estímulo para aumentar su cantidad, con lo que a la larga bajaría el precio hasta que quedara equilibrado».

44 Townsend (1988 [1791], pp. 294-299); véase también Jardine (2001 [1788], pp. 217, 313314, 379). Jardine (2001 [1788], p. 379) y Townsend sólo aceptaban una posible excepción para la concesión de un monopolio comercial: «si un territorio libre y rico en capitales estuviera aún incivilizado, o si para una empresa arriesgada se precisaran sumas mayores que las que podría reunir el crédito de una compañía privada» (Townsend, 1988 [1791], p. 295). Con todo, el principio general estaba claro: «El sistema moderno de colonización y acaparamiento a toda costa del comercio (colonial) acaba siendo destructivo [...](Lo idóneo) es dejar que sea el comercio el que encuentre por sí mismo sus propios canales adecuados, su nivel y sus límites» (Jardine, 2001 [1788], p. 312).

${ }^{45}$ Un paso importante en este sentido fue el Reglamento y aranceles para el comercio libre de España e Indias de 1778. Según Delgado Ribas (1995, p. 27), el desarrollo del mercado colonial durante la época del despotismo ilustrado fue importante para muchas industrias españolas (construcción naval, papelera, sedera, de curtido, etc.), pero no así para la industria algodonera catalana - clave en lo que luego sería la industrialización española_, cuyo nacimiento no estuvo ligado al citado desarrollo del comercio colonial.

46 Jardine (2001 [1788], p. 336; ver también pp. 195 y 315). Townsend (1988 [1791], p. 299) y Townsend (1786, p. 4). 
Townsend y Jardine llegaban incluso a plantear la conveniencia de que España se deshiciese de sus colonias, dado el enorme gasto militar qe suponían en relación a los beneficios que reportaban a la metrópoli ${ }^{47}$.

En cuanto al comercio interior, Jardine destaca su carácter escaso, la reducida gama de artículos entre los que escoger y la poca integración del mercado, con notables diferencias en los jornales y en los precios de los productos básicos incluso entre regiones no demasiado lejanas (Jardine, 2001 [1788], p. 291). Además, era frecuente el cobro de peajes en los caminos, pero sin que ello contribuyera a mejorar el estado de los mismos (Jardine, 2001 [1788], p. 321).

En la línea de Smith, la agricultura era considerada el sector básico por los viajeros ${ }^{48}$, quienes, con excepción del levante, observaban en el caso español un notable atraso y una situación de decadencia agrícola ${ }^{49}$. Sin duda, la propia experiencia británica, donde la revolución agrícola y el proceso de cercamientos habían dado lugar ya a finales del siglo XVIII a unos resultados impresionantes en términos de productividad, pesaba mucho en su valoración. Townsend, que describió minuciosamente los diferentes tipos de instrumentos agrícolas que encontró a su paso (arados, norias, etc.), transmite la idea de una tecnología en general anticua$\mathrm{da}^{50}$. Además, echaba en falta «un poderoso grupo de arrendatarios ricos» como

47 Por ejemplo, Townsend (1988 [1791], p. 304) señala: «España sería más rica y poderosa si prescindiera de sus colonias», pues «el dinero que anualmente destina a (convertirse en una potencia naval para proteger el comercio colonial y asegurar sus monopolios) sería más útil si se empleara en promover la industria y la agricultura, abrir comunicaciones, fomentar la producción (o) estimular el comercio». La postura de Jardine, más política, se aproxima en cierto modo a la que años después defendería Bentham en Libraos de Ultramar (1820-2): una verdadera transformación del despótico régimen político español conllevaría necesariamente desprenderse de los dominios de ultramar (Rodríguez Braun, 1989, p. 124). En España, a principios del siglo XIX, Valentín de Foronda llegó a proponer la venta de las colonias en su Carta sobre lo que debe hacer un príncipe que tenga colonias a larga distancia, escrita en 1800 y publicada en 1803 (véase la voz Foronda en Perdices y Reeder, 2003, pp. 498-501).

48 «Un soberano prudente debería estimular a sus súbditos a buscar los beneficios más lentos, pero más seguros, más moderados, pero también más regulares, de la agricultura. La afición a la minería debería ser la última en estimularse» (Tonwsend, 1988 [1791], p. 429). Townsend (1988 [1791], p. 400) también situaba a la agricultura delante de la industria y el comercio: «Cuando tenga que decidirse a favor de la agricultura o de la industria España no debería dudar en dar preferencia a la primera, pues es más beneficiosa para el Estado». Es destacable que casi todos los viajeros británicos que visitaron España a lo largo del siglo XVIII mostraran un particular interés por las prácticas agrícolas y el estado de los conocimientos agronómicos. A este respecto, véase el trabajo de Guerrero (1988).

49 Sólo los alrededores de Barcelona y las huertas valenciana y murciana llamaron poderosamente la atención de Townsend por su buen cultivo (Townsend, 1988 [1791], pp. 75; 361; 403). Jovellanos (1983 [1795]), a diferencia de la mayoría de sus contemporáneos, negó la extendida idea de decadencia de la labranza en España, que también defendían los viajeros británicos.

50 Véase también, por ejemplo, Jardine (2001 [1788], pp. 198-199). 
el que existía en Inglaterra ${ }^{51}$, y criticaba el absentismo de los propietarios que preferían «dejar sus tierras en administración» ${ }^{52}$, así como las inmensas posesiones de los pueblos andaluces, a menudo sin cultivar (Townsend, 1988 [1791], p. 264). Por otra parte, la vinculación de gran número de tierras hacía que fuese «poca la tierra que (llegaba) a salir al mercado», y tal freno «a la circulación de la propiedad (acababa suponiendo) un enorme obstáculo para el progreso», reforzando además la tendencia a la concentración de la propiedad (Jardine, 2001 [1788], pp. 166; 346-347). Los mayorazgos, asimismo, eran problemáticos porque no se permitía conceder sobre ellos arriendos a largo plazo ${ }^{53}$. Dos problemas adicionales afectaban a la agricultura: la falta de riegos y la falta de mercados (Jardine, 2001 [1788], pp. 308-309). El primer aspecto conectaba con la ausencia de una política hidráulica efectiva (Townsend, 1988 [1791], pp. 377; 413), mientras que el segundo, la escasa comercialización, se relacionaba entre otras cosas con unas infraestructuras deficientes que no facilitaban la distribución — algo a lo que ya se ha hecho referencia- . Townsend también se refería a que la labranza y la ganadería cometían en vez de complementarse, y dado que la ganadería trashumante disfrutaba de especiales privilegios gracias a la Mesta, ello conducía a un escaso desarrollo del cultivo y a la despoblación interior ${ }^{54}$. En cuanto a la experiencia colonizadora de Sierra Morena, tanto Jardine como Townsend alababan la iniciativa de Olavide, pero la consideraban un fracaso, dado que las nuevas poblaciones que visitaron languidecían ${ }^{55}$. Por último, ambos se referían a la expulsión de los moriscos como un error irreparable que aún entonces seguía dejando sentir sus efectos, al haber supuesto la pérdida de una población laboriosa y frugal que conocía bien las técnicas del riego y del cultivo del arroz, el algodón, la caña y las moreras, y que además tenía un protagonismo importante en el comercio y en determinadas industrias como la seda, el papel o la pólvora ${ }^{56}$.

${ }^{51}$ En realidad, en España sí había grandes arrendatarios y contratos de arrendamiento a largo plazo. El problema resultaba, por tanto, bastante más complicado que lo apuntado por Townsend a la hora de comparar con su país de origen en este aspecto.

52 «Nosotros hemos descubierto que la riqueza genera riqueza, y que para extraerla de la tierra es necesario que parte de ella llegue al bolsillo del granjero. Muchos de nuestros caballeros, llevados por el deseo de entretenerse o buscando rentabilizar su dinero, se han dedicado a la agricultura, [...] han producido ricas cosechas y han perfeccionado los sistemas de labranza (Townsend, 1988 [1791], p. 197). Ver también Jardine (2001 [1788], p. 310).

53 Véase Jardine (2001 [1788], p. 408n). Tanto Townsend como Jardine prestaron gran atención a las posibilidades de arriendo de tierras. Sólo los arriendos a largo plazo de Cataluña despertaron el elogio de Townsend (1988 [1791], pp. 422-423). Jardine (2001 [1788], p. 232) alabó los «foros» gallegos, aunque destacando el problema de los subarriendos.

54 Townsend (1988 [1791], pp. 180-181; 190; 264).

55 Sobre los problemas del proyecto colonizador olavideño véase Perdices (1992, pp. 521-522). Algunos de estos problemas fueron ya parcialmente apuntados por los propios viajeros: véase Jardine (2001 [1788], pp. 280-282) y Townsend (1988 [1791], pp. 258-259).

56 Townsend (1988 [1791], pp. 334-5); Jardine (2001 [1788], p. 337). 
Finalmente, la manufactura también causó una pobre impresión a los viajeros, que vieron en las iniciativas gubernamentales una política colbertista. Townsend, que dio cuenta de todas la Reales Fábricas que encontró a su paso ${ }^{57}$, condenó sin ambages este tipo de establecimientos, muchos de ellos centrados en bienes de lujo: «el monarca (convertido en fabricante) siempre será un perdedor, incluso donde la iniciativa privada se las ingenia para ganar», dados «los salarios que debe pagar, el escaso atractivo de la diligencia y la austeridad, el mucho que tienen la negligencia y la rapiña, y cuán débil es el aliciente que encuentran los trabajadores para superarse» (Townsend, 1988 [1791], pp. 113; 101). Jardine, por su parte, calificaba también las manufacturas reales de proyectos grandiosos, caros e ineficaces, criticando asimismo la habitual concesión de privilegios y monopolios exclusivos (Jardine, 2001 [1788], pp. 194-195). En otro orden de cosas, y partiendo de la idea de que existían países aptos para producir materias primas y países preparados para manufacturarlas, Jardine entendía que era ya «demasiado tarde» para introducir determinadas manufacturas en España: primero, porque «un oficio necesita a menudo de otros cientos para poder desarrollarse, y sería imposible encontrar la mitad de ellos en el país» (Jardine, 2001 [1788], p. 213); y segundo, porque España sería incapaz de competir con una industria ya establecida en otros países con precios menores y amplios mercados ${ }^{58}$ (Jardine, 2001 [1788], pp. 193-194). Sólo la manufactura del algodón en Barcelona, la de la seda en Valencia y la del hierro en el País Vasco parecían merecer claros elogios.

\section{JARDINE Y TOWNSEND EN RELACIÓN A LOS ILUSTRADOS ESPAÑOLES}

\subsection{Conocimiento y valoración de los autores españoles}

En general, la veintena larga de viajeros británicos que visitaron la Península en el siglo XVIII mostraron un escaso conocimiento de los autores españoles. Así

\footnotetext{
57 La de tabaco en Sevilla, la de armas en Toledo, la de medias en Valdemoro, la de vidrio en La Granja, la de paño en Guadalajara, y las de porcelana, tapices y naipes en Madrid. Asimismo visitó las reales industrias de salitre en Madrid y otras localidades. Cita además las reales fábricas de papel en Segovia, de paños en Brihuega, de naipes en Málaga, y de cerámica y tejidos de seda en Talavera (Townsend, 1988 [1791], p. 246).

58 «Primero hay que establecer cierto grado de libertad y seguridad y así, más tarde, la industria, que es la verdadera riqueza, irá creciendo poco a poco hasta producir sus propios signos: el dinero, las existencias, el crédito. Mientras el dinero o cualquier otro de los signos o medidas arbitrarias de riqueza entren a raudales en un país antes de ese periodo, éste no servirá para fomentar la aparición de la industria, sino para impedirla» (Jardine, 2001 [1788], p. 194). Véase también Townsend (1786, p. 7).
} 
lo asevera Freixa (1991, p. 499), quien además considera que la relación de nombres que citan «da la sensación de ser totalmente azarosa» y se circunscribe a «los que han adquirido fama internacional», como Mariana, Uztáriz, Ulloa, Campomanes, Feijoo o Isla. Esta última afirmación es particularmente cierta en el caso de Jardine, que - por las referencias que cita- sólo parece haber leído ampliamente a Campomanes, a Feijoo y al Mariana historiador. Townsend, sin embargo, muestra un conocimiento mucho más amplio: además de a los tres autores anteriores, cita con profusión la obra de Uztáriz y Ulloa — que muy probablemente había conocido a través de La Riqueza de la Naciones ${ }^{59}$-, y también se refiere a Ward o Zavala, así como a algunos arbitristas del siglo XVII como Caxa de Leruela, Moncada y Martínez de Mata - a quienes seguramente conociera de forma indirecta a través de Campomanes ${ }^{60}$ - . Asimismo, Townsend también demuestra estar algo mejor informado que Jardine por lo que se refiere a las principales actuaciones económicas de ministros como Ensenada, Esquilache, el conde de Aranda o Floridablanca.

En cualquier caso, y como no podía ser de otra manera, el referente esencial para ambos viajeros es Campomanes, el economista más importante del reinado de Carlos III, que marca una época con nombre propio en el pensamiento español entre 1760 y 1780 (Llombart, 2000, p. 15). Townsend cita prolijamente su Discurso sobre la educación popular de los artesanos (1775), y - en menor medida- su Discurso sobre el fomento de la industria popular (1774) (Rodríguez Campomanes, 1975a), mientras que Jardine, sin mencionarlos explícitamente, también parece conocer bien ambos escritos, así como el Tratado de Regalía de Amortización (1765) (Rodríguez Campomanes, 1975b) ${ }^{61}$. Townsend, además, trató personalmente a Campomanes, quien tras una primera impresión de hombre «adusto y de modales bruscos», se comportó siempre de forma «amable, cordial, amigable y servicial hasta no poder más» ${ }^{62}$, proporcionándole cartas de recomendación e invitándole a su tertulia (Townsend, 1988 [1791], pp. 114-115). No es de extrañar entonces que Townsend tuviera una elevada opinión de

59 Smith cita a Uztáriz en relación a las alcabalas (Smith, 1987 [1776], p. 926), y a Ulloa en referencia a temas tan diversos como el valor relativo del pan y la carne en Buenos Aires, las condiciones de explotación de las minas del Perú, la población de algunas ciudades de Chile y Perú, o el comercio con las colonias españolas (Smith, 1987 [1776], pp. 227, 248-249, 266, 283, 610, 617).

60 En los Apéndices a la Educación Popular Campomanes reeditó a Martínez de Mata, mientras que Moncada y Leruela ya habían sido reeditados en 1746 y 1732 respectivamente (Perdices, 1996, pp. 168-169; 199). Campomanes consideraba a los tres como autores de obras «útiles» que debían leerse en las sociedades económicas, y pudo aconsejar también su lectura a Townsend (Rodríguez Campomanes, 1975 [1774], p. 112n).

61 Véase Townsend (1988 [1791], pp. 101, 240-249, 299, 301, 334, 371 y 375). Véase también Jardine (2001 [1788], pp. 215-216, 247, 278, 405).

${ }^{62}$ Para una posible explicación del recelo inicial de Campomanes véase Reeder (1975, pp. 22-24). 
Campomanes, a quien califica de gran erudito y estadista capaz (Townsend, 1988 [1791], pp. 101, 251). Sin embargo, la opinión de Jardine era menos favorable, pues le consideraba

«un poco limitado en exceso en las lecturas y los sistemas franceses, [...] algo carente de observación y viajes, [...] (y) sujeto a algunos de los antiguos perjuicios, como son la necesidad de prohibiciones estrictas, el hacer de España un país de manufacturas antes casi de que aumente su población y su cultivo, el de observar el equilibrio de la balanza comercial y el esperar que el gobierno lo regule todo» (Jardine, 2001 [1788], pp. 215-216).

Con todo, Jardine veía en él al mismo tiempo a un hombre de «gran mérito», «lleno de conocimientos útiles», y lo suficientemente «franco y tolerante» como para ir cambiando de ideas, de forma que «sus últimas publicaciones son siempre las mejores». En este sentido, Jardine (2001 [1788], pp. 215-216) creía que «cuando (llegase) a leer a Adam Smith» ${ }^{63}$ contemplaría más claramente «las imperfecciones de la forma actual de gobierno». Por otra parte, consciente del proceso que se había seguido contra Olavide, Jardine (2001 [1788], p. 217) veía peligrar a Campomanes: «puede que todavía tenga el honor de acabar sus días en manos de la Inquisición».

Por lo que respecta al contacto directo con otros ilustrados importantes, Townsend trató también personalmente a Floridablanca, a quien alude con palabras de gratitud y admiración ${ }^{64}$, y a Cabarrús, a quien se refiere como persona poseedora «de un gran talento, una mente despejada y una gran facilidad de palabra», haciendo luego una descripción neutra y bastante detallada de las actividades del Banco de San Carlos ${ }^{65}$. Por su parte, Jardine - tras su vuelta a España como cónsul en 1793 - conoció personalmente a Jovellanos y mantuvo una relación epistolar con él entre 1793 y 1796. Sin embargo, Jardine había radicalizado sus posiciones políticas desde su anterior estancia en España. Ahora, en vez de las ideas de monarquía limitada y división de poderes que había defendido en las Cartas, se mostraba partidario de los principios revolucionarios que habían propiciado el cambio político en Francia en 1789. Sin embargo, esta nueva actitud no casaba con el reformismo gradualista de Jovellanos, que cada vez se fue mostran-

${ }^{63}$ Cuando Jardine publica su libro en 1788 Campomanes conocía ya la obra de Smith, pues fue el primer economista español que, hacia 1777, tomó contacto con La Riqueza de las Naciones —la traducción de un fragmento del capítulo décimo-. En 1785 dispuso de la obra completa (véase Llombart, 1992, pp. 296-305).

${ }^{64}$ Véase, por ejemplo, Townsend (1998 [1791], pp. 118, 132).

65 Townsend (1988 [1791], p. 233). Véase también la p. 123. 
do más molesto con las opiniones del inglés, hasta que finalmente el intercambio epistolar se interrumpió ${ }^{66}$ (Sarrailh, 1992, pp. 319-320).

\subsection{Coincidencias y discrepancias con los ilustrados españoles de la segunda mitad del siglo XVIII}

La práctica totalidad de las cuestiones que preocuparon a los ilustrados españoles aparecen reflejadas — con mayor o menor amplitud— en la obra de los dos viajeros: el socorro de pobres, la necesidad de reformar y simplificar el sistema fiscal para eliminar desincentivos a la industria y el comercio, la discusión sobre la conveniencia de las fábricas reales y las posibilidades de promoción de la manufactura, la reforma de los gremios, el sistema de comercio colonial, el fomento de la población, o los problemas del sector primario — tales como la concentración de tierras, la amortización eclesiástica, los mayorazgos, los privilegios de la Mesta, el absentismo de los propietarios, la regulación de los arrendamientos, la importancia del libre comercio de granos, y el atraso en los conocimientos y las técnicas agrícolas-. Y es que, en lo que se refiere a la identificación de los problemas económicos concretos asociados a los distintos sectores productivos —especialmente el agrícola—, hay una coincidencia básica entre los dos viajeros y los ilustrados españoles de la segunda mitad del siglo XVIII. En particular, Townsend y Jardine se apoyan en Campomanes - quien participó de forma decisiva en la orientación de todos los debates económicos ilustrados ${ }^{67}$ — para conformar su propia visión de la realidad española, tanto como fuente de información sobre aspectos específicos de la economía (datos sobre población, manufacturas, etc.), como en términos de identificación de obstáculos — morales, legales y físicos - y posibles vías concretas de solución.

Sin embargo, es a la hora de enjuiciar el sistema político, la situación económica general y ciertas actitudes gubernamentales, basadas aún en planteamientos mercantilistas, cuando surgen discrepancias entre los ilustrados y los viajeros — dos firmes defensores del liberalismo económico-. Townsend y Jardine reconocían los esfuerzos reformistas de los ilustrados y algunos logros concretos, como la consecución de la libertad de comercio interior de granos. Pero conside-

${ }^{66}$ La penúltima anotación de Jovellanos en sus Diarios en relación a la correspondencia con Jardine dice así: «Carta larga a Jardine, entrando, en fin, en hablar de sus sueños filosóficos; dígole que por la última vez, mi poca afición a ellos» (Jovellanos, 1954, p. 221; entrada 23/2/1796). Y la última: «Jardine siempre con sus manías» (Jovellanos, 1954, p. 264; entrada 25/7/1796). Para una amplia discusión de la relación Jovellanos-Jardine véase Pérez Berenguel (2001, pp. 83-93).

67 Véanse en este sentido las voces dedicadas a los debates del siglo XVIII en Perdices y Reeder (2004). 
raban que tales esfuerzos reformistas habían derivado a menudo en un excesivo intervencionismo ${ }^{68}$, quedando casi siempre en una mera operación de parcheo:

«Los gobiernos absolutos no pueden mejorarse por el añadido de pequeñas disposiciones y subdivisiones [...] Puede que dichos gobiernos sean administrados a veces por hombres buenos, tal y como parece ocurrir en la actualidad, y entonces puede que se emprendan algunas pequeñas mejoras. Pero esta nación parece demasiado hundida para que vuelva a alcanzar de nuevo algún lugar de importancia mediante disposiciones pequeñas y provisionales. Resulta evidente que estos ministros pueden hacer escaso bien o ninguno. [...] ¡Los sistemas y las instituciones falaces no responden a ninguno de los fines que se espera de ellos! [...] El poder humano y el interés particular no pueden ponerse límites a sí mismos [...] El gobierno, o la sociedad, debería tener un sistema de comprobaciones o de control mutuo» (Jardine, 2001 [1788], pp. 355-356).

En suma, sin un profundo cambio del sistema político - desde el despotismo arbitrario hacia el gobierno representativo con libertades civiles - no habría posibilidad de mejora real. Es decir, el país no podría salir de la situación de decadencia general que los dos viajeros diagnosticaban, muy mediatizados por la tendencia a comparar la realidad española con la de su país de procedencia. Las «absurdas prohibiciones, monopolios e impuestos opresivos», en concreto, se veían como una característica inherente a la forma de gobierno despótico, y era precisamente en el ámbito del comercio colonial —en el que primaba la política proteccionista asociada al «mercantilismo liberal» de Campomanes-donde se focalizaban las críticas más duras de Townsend y Jardine. Así, por ejemplo, aunque los esfuerzos de reforma del sistema del comercio colonial español para liberalizar los intercambios dentro del Imperio eran reconocidos por ambos ${ }^{69}$, los consideraban del todo insuficientes:

«El gobierno español aún no tiene ideas liberales respecto al comercio; e incluso algunos de sus mejores escritores políticos se asemejan a sabuesos lentos que van tras el olor que ha dejado una presa que otros más veloces ya han atrapado. En vez de eliminar todos los obstáculos que restringen el comercio, se afanan por estrechar sus límites con la absurda esperanza de

${ }^{68}$ Los legisladores «con un celo excesivo (y) aun con buenas intenciones, pueden acabar con las energías y los deseos de mejorar de los hombres, con ese afán por regularlo todo» (Jardine, 2001 [1788], p. 233).

${ }^{69}$ La liberalización del comercio americano se hizo siguiendo las ideas de Campomanes, pero éste deseaba una liberalización más amplia que la que acabó cuajando efectivamente. 
crear un monopolio, sin tener en cuenta su propia falta de capital, de laboriosidad y de espíritu emprendedor y la total imposibilidad de evitar el contrabando. [...] (Pero) todas sus prohibiciones [...] resultarán frívolas y vanas, pues cualquier esfuerzo que esté en contra de los intereses de sus propios súbditos y de las naciones vecinas no les servirá para nada» (Townsend, 1988 [1791], p. 293).

Los ilustrados españoles, por su parte, tenían una visión bien diferente, tanto respecto a la situación económica general del país, como respecto a las posibilidades que ofrecía el sistema político de cara al desarrollo y a lo que debía ser la orientación de la política pública en el ámbito industrial y comercial ${ }^{70}$. En primer lugar, y a diferencia de los viajeros, el diagnóstico de los ilustrados de la situación económica no era en absoluto negativo: siguiendo la línea marcada por Bernardo Ward en su Proyecto económico (1762), todos ellos iban a mostrar un claro optimismo en relación a las posibilidades de crecimiento de la economía española, pese a reconocer el atraso relativo frente a las grandes potencias europeas de la época. Lo que había que lograr era ocupar con utilidad «tierras, hombres y dinero», o como señalara Francisco Romà y Rosell en Las señales de la felicidad (1768), conseguir la máxima población ocupada productivamente ${ }^{71}$.

En segundo lugar, los ilustrados españoles —desde economistas como Campomanes y Enrique Ramos, hasta miembros de la ilustración tardía, como Jovellanos o Cabarrús - mostraron en general una firme confianza en el absolutismo ilustrado como forma de gobierno que permitía avanzar hacia el progreso, siempre con el apoyo ofrecido por ese valioso instrumento que era la economía política ${ }^{72}$. En este punto resulta evidente la disparidad entre tal actitud y los recelos mostrados por Townsend y Jardine hacia el despotismo borbónico.

En tercer lugar, el agrarismo más o menos matizado de la mayoría de los ilustrados españoles — que les llevaba a considerar la agricultura como el principal fundamento de la riqueza ${ }^{73}$ - se combinaba con una insistencia general en la necesidad de desarrollo industrial, insistencia que contrastaba con la idea de los viajeros británicos de que España debía concentrar todos sus esfuerzos en el sector primario ${ }^{74}$. Así, desde Ward en adelante los ilustrados iban a reconocer con

\footnotetext{
${ }^{70}$ Salvo indicación concreta, en los párrafos que siguen me apoyo en la gran síntesis del pensamiento económico ilustrado español realizada por Vicent Llombart (2000), así como en su discusión de las convicciones agraristas y el pragmatismo industrialista desde Ward a Jovellanos (Llombart, 1997).

${ }^{71}$ Lombart (2000), pp. 20; 27.

72 Llombart (2000), pp. 22; 28; 36; 45.

${ }_{73}$ Como indica Ocampo (2003), p. 94, existía una amplia unanimidad entre los ilustrados en que «la agricultura y la población constituían prioridades indiscutibles cualquiera que fuese el modelo de desarrollo» para converger con las «naciones industriosas» europeas.

${ }^{74}$ Llombart (1997), pp. 71-80.
} 
generalidad que las actividades manufactureras y comerciales eran complementarias de la agricultura. Es más, economistas como Campomanes, Romà, Ramos o Arriquíbar iban incluso a subrayar su estrecha interrelación e interdependencia. Enrique Ramos, por ejemplo, en su Discurso sobre economía política (1769), destacaba cómo el crecimiento agrario llevaba a la abundancia y mejor precio de alimentos y materias primas, a un aumento demográfico, de la demanda de productos industriales y de los intercambios de bienes, y a un incremento de las manos disponibles para las actividades industriales; a su vez, las actividades industriales y comerciales daban mayor valor a las producciones agrícolas y mejoraban la balanza de comercio con otros países ${ }^{75}$. Por su parte, Nicolás de Arriquíbar destacaba en su Recreación política (1779) que las mayores posibilidades de crecimiento estaban en la industria y el comercio, dada la capacidad prácticamente ilimitada de producción y consumo en ambos sectores ${ }^{76}$; en esta misma dirección apuntaba también Jovellanos en su «Informe sobre el libre ejercicio de las artes» (1785), al referirse a que la esfera de la industria era de «inmensa extensión», mientras que el terreno cultivable tenía sus límites señalados por la naturaleza. Donde surgían diferentes visiones era en relación a la forma que debía adoptar el desarrollo industrial, con propuestas que iban desde el sistema de putting-out defendido por Ward y Arteta, hasta la industria popular o producción artesnal independiente por la que abogaban Campomanes y Jovellanos. Con todo, en ningún caso hubo una oposición frontal al modelo centralizado de fábricas instaladas en grandes edificios y basadas en el trabajo asalariado, sino que dominó el pragmatismo, abierto a apoyar cualquier tipo de establecimiento industrial que proporcionara ocupación útil y satisficiera las necesidades de consumo ${ }^{77}$. Respecto a los gremios, sólo los economistas catalanes — Romà, Capmany o Caresmarfueron partidarios de su mantenimiento sin grandes reformas, por considerarlos importantes para el desarrollo de la manufactura ${ }^{78}$.

Por último, en cuarto lugar, para fomentar la «naciente» industria nacional hay una acuerdo general entre los economistas españoles de la segunda mitad del siglo XVIII - Ward, Campomanes, Romà, Ramos, Arriquíbar, etc.- en protegerla del resto del mundo, protección a la que añaden otras medidas adicionales tales como ayudas fiscales, mejoras en las comunicaciones, reconocimiento de la honradez de los oficios, o introducción de artesanos extranjeros. Incluso ilustrados tardíos como Jovellanos y Cabarrús — a los que a veces se ha presentado como abso-

\footnotetext{
${ }^{75}$ Llombart (2000), p. 28.

76 Astigarraga y Barrenechea (1987), pp. 32-33.

77 Llombart (1997), pp. 73; 77

${ }^{78}$ Lluch (2000), p. 580. En cualquier caso, los puntos de encuentro entre las propuestas industrialistas periféricas y castellanas resultan mucho más significativos que las puntuales discrepancias (Ocampo, 2003, p. 94).
} 
lutos librecambistas - o como Alonso Ortiz y Alcalá Galiano — que se ocuparon respectivamente de la traducción y la síntesis de la obra de Adam Smith- defendieron la política de protección de la manufactura frente al exterior que tantas criticas suscitaba entre los viajeros británicos. Esta defensa no era arbitraria o gratuita, sino que se insertaba en un programa amplio y razonado de desarrollo económico — el de la ilustración española — que a partir de Campomanes fue siendo reformulado y actualizado por sucesivos autores sin rupturas, manteniendo siempre las mismas líneas básicas. Desde el reconocimiento del interés particular como estímulo esencial para el desarrollo de actividades económicas, y dentro de un marco de proteccionismo respecto al exterior, se buscaba una gradual liberalización económica interior junto a la aplicación de medidas concretas de fomento de la agricultura y la manufactura, llevadas a cabo por un Estado fortalecido frente a poderes, estamentos e instituciones que pudieran plantear dificultades ${ }^{79}$.

Finalmente, vale la pena detenerse a comentar brevemente las recomendaciones de tipo general de Townsend y Jardine, que — siendo plenamente coincidentes entre sí- estaban muy lejos de las de los ilustrados españoles. Dichas recomendaciones eran las siguientes: «proteger a las personas y a las propiedades de la tiranía real mediante libertades civiles» ${ }^{80}$ («restableciendo las antiguas Cortes [...] con una representación más equitativa y adecuada»), «liberalizar el comercio y vivir en paz», buscar la especialización en el sector primario, practicar la tolerancia religiosa y «expulsar a los inquisidores», y emancipar las colonias ${ }^{81}$. Al respecto, cabe hacer dos consideraciones importantes.

Por un lado, se trata de propuestas interesadas, que se entienden mucho mejor si se tiene en cuenta la fuerte rivalidad económica, militar y comercial que existió entre los países europeos durante todo el siglo XVIII, y a la que ya se hizo referencia anteriormente (Llombart, 1988, pp. XXXI-XXXII). En realidad, el que España abandonase sus colonias, declarase un completo librecambio, o renunciase al desarrollo de la manufacturas para dedicarse sólo a la agricultura — algo que como se ha visto rechazaron de plano autores como Ward, Romà, Campomanes o Arriquíbar-, beneficiaba claramente a Inglaterra. Además, aunque Jardine y Townsend parecen partir del supuesto de que en Inglaterra existía el libre comer-

79 Llombart (2000), p. 24.

${ }^{80}$ Los viajeros asociaban las regiones de mayor actividad económica en España con la existencia de mayores libertades y menores arbitrariedades del poder real. Por ejemplo, Jardine (2001 [1788], p. 171) vinculaba la relativa prosperidad que observaba en el País Vasco y Navarra al hecho de ser «reductos de libertad», donde el Estado había dejado que hicieran sus propias leyes, cobrasen sus propios impuestos y gobernasen sus propios asuntos. Townsend (1988 [1791], p. 422), por su parte, consideraba que la industria de Cataluña había escapado a la insensata opresión fiscal, pues disfrutaba de la ventaja de «estar libre de la influencia paralizadora de la alcabala, los cientos y los millones».

${ }^{81}$ Townsend (1988 [1791], pp. 102 y 430); Jardine (2001 [1788], pp. 221-222). 
cio, esto no era cierto, pues la práctica de la política económica inglesa — lejos de las ideas liberales de Hume y Smith - estuvo marcada durante toda la centuria ilustrada por una orientación proteccionista e intervencionista, como en el resto de los países europeos ${ }^{82}$. De hecho, a lo largo de la década de 1770 dicha política alcanzó un punto álgido en su proteccionismo. Por ello, no deja de resultar irónico que ambos viajeros se permitieran acusar a políticos y escritores españoles de atraso en las ideas por no aceptar los principios del librecambio. Y es que lo que sucedía, con carácter general, era que «el proteccionismo industrial practicado para su propio país por parte de Inglaterra [...] se (transformaba) en una especie de liberalismo agrario de exportación para países de atraso relativo como España» (Llombart, 1997, p. 82).

Por otro lado, en muchos aspectos estamos ante propuestas de transformación radical del statu quo que no casaban bien con el reformismo ilustrado. Pero la crítica implícita de los viajeros británicos a los ilustrados españoles por no poner en cuestión el despotismo ilustrado y el orden establecido —optando a cambio por una vía posibilista y gradualista - resultaba en realidad injusta, aunque luego se haya repetido en numerosas ocasiones. Así lo plantea Vicent Llombart (1992, pp. 359-360):

«Se afirma que la actitud respetuosa (de los ilustrados españoles) con el orden social estamental o con los aspectos estructurales del Antiguo Régimen conducía irremediablemente al fracaso de unas actuaciones meramente cosméticas. [...] En primer lugar, es cierto que a pesar de que a los ilustrados no les gustaba la sociedad en que vivían, su concepción del futuro en 1789 permanecía en los límites de lo que hoy llamamos Antiguo Régimen, al que pretendían reformar y no sustituir plenamente. En segundo lugar, en el terreno de la política siempre fueron pragmáticos, realistas y gradualistas, por lo que aunque hubiesen tenido un horizonte ideológico más amplio posiblemente no hubiesen deseado seguir un camino diferente. [...] Y en tercer lugar, aunque hubieran pretendido lo que hoy denominamos en un tono ampuloso reformas estructurales o cambio estructural en

${ }^{82}$ Lo que inspiró el «mercantilismo liberal» de Campomanes no fue sino su admiración por la política económica seguida por Inglaterra en la segunda mitad del siglo XVII, que — apoyada en el pensamiento económico de los mercantilistas ingleses - había cimentado lo que el asturiano llamó la «revolución mercantil» inglesa (Campomanes, 1988 [1762], p. 242). Los efectos más destacados de dicha revolución se produjeron en el siglo XVIII, durante el que se mantuvo la orientación proteccionista e intervencionista (Llombart, 1988, p. XXIV). En este sentido, es importante destacar que «las tendencias básicas de la política comercial e industrial española aplicada entre 1760 y 1790 se asemejan a las que continuaba adoptando Inglaterra a partir de un pragmático pero inequívoco proteccionismo industrial, [...] y de una mayor libertad económica interior de facto» (Llombart, 1997, p. 81). 
forma rápida, nada hubieran conseguido, pues ni existía un grupo social que presionara en este sentido ni la propia monarquía lo hubiese aceptado. Ese pretendido cambio estructural era algo no deseado y además una imposibilidad política. La menos espectacular vía reformista al menos podía lograr ciertos resultados hacia una sociedad más abierta en algunas esferas».

Sólo algunos miembros de la Ilustración tardía empezaron a establecer una clara relación entre cambio político y prosperidad económica. Así, por ejemplo León de Arroyal propuso en sus Cartas económico-políticas - fechadas entre 1786 y 1795 - un borrador de Constitución que limitase los poderes del monarca y estableciera la división de poderes, basándose en la tradición aragonesa, en la Constitución revolucionaria francesa y en los principios de racionalidad de la Ilustración. El hecho de que no se hubiera establecido una regla segura de gobierno - en forma de Constitución - que propiciara la libertad civil y la seguridad jurídica, era para Arroyal la clave para entender por qué las propuestas de reforma económica se habían quedado sólo en buenas intenciones ${ }^{83}$. Del mismo modo, Foronda, tras su regreso de Estados Unidos donde permaneció como cónsul hasta 1809, «parece comprender perfectamente que el marco jurídico y político en el que se desarrolla la vida económica ha de alterarse profundamente» (Barrenechea, 2000, p. 562). Pero será a partir de las Cortes de Cádiz cuando la idea de que la abolición de las antiguas cortes y el prolongado triunfo del despotismo habían llevado a la nación a la ruina — tan ponderada por los viajeros británicos del dieciocho- se convertirá en una constante en el pensamiento liberal español ${ }^{84}$.

\section{CONCLUSIÓN}

Los amplios recorridos por la España de Carlos III que realizaron Joseph Townsend y Alexander Jardine resultan ser en buena medida complementarios, al igual que sucede con sus respectivas aproximaciones a los problemas del país. De este modo, entre los dos consiguen dibujar una imagen de conjunto bastante completa y coherente. La visión que dan de la economía y la sociedad españolas reviste especial interés porque aporta una perspectiva distinta, menos positiva que la que hoy manejamos sobre el mismo periodo y también menos favorable que la que

${ }^{83}$ Perdices y Reeder (2003, pp. 62-63). Sobre los precedentes de las ideas liberales en los escritos de los ilustrados véase Elorza (1970).

${ }^{84}$ Esta es una de las conclusiones básicas que cabe extraer del amplio estudio de De la Iglesia (1994). 
tenían los propios ilustrados. Ciertamente, es la suya una mirada muy condicionada por factores tales como la premura del viaje, los viejos clichés sobre España reflejados en las geografías británicas del siglo XVII, o la propia realidad de su país de origen. Sin embargo, se trata también de la penetrante mirada de dos hombres típicos de la Ilustración, de amplia formación, inquietudes intelectuales y capacidad analítica, que están al tanto de los debates de la Europa de su tiempo y que muestran un notable interés por los aspectos socioeconómicos. Imbuidos de la idea del viaje ilustrado, pretendían ante todo que de sus crónicas pudieran desprenderse enseñanzas útiles, que en el caso de España pasaban por el aprendizaje de los errores que habían conducido a un país en otro tiempo hegemónico a una situación de prolongada postración. Pero además, en un momento de fuerte rivalidad entre España y Gran Bretaña, la información económica que trasmitían podía llegar a ser crucial en caso de guerra.

Más que los datos concretos que aportan, generalmente de segunda mano y a veces de dudosa fiabilidad, interesan los análisis que realizan, que reflejan —entre otras cosas - la difusión de determinadas concepciones económicas. Concretamente, los dos libros de viajes aquí considerados son buenas muestras de la temprana penetración en Gran Bretaña de las ideas del liberalismo económico, ideas que llevaron a ambos viajeros a adoptar una óptica crítica al aproximarse al análisis de la economía española aún dominada por ciertas prácticas mercantilistas. Asimismo, tienen el mérito de no haberse dejado llevar completamente por los estereotipos heredados de finales del siglo XVII, que eran muy negativos y que ellos contribuyeron en parte a revisar, lo que denota un criterio propio y abierto. En este sentido, conviene tener presente que España había quedado al margen del Grand Tour como nación periférica y culturalmente desprestigiada, presa de una serie de tópicos simplificadores. A pesar de todo, es cierto que las visiones de Townsend y Jardine aún están llenas de prejuicios — quizá interesados—, falsa superioridad e incluso errores de bulto, y que además adolecen de un escaso uso de la literatura económica española. Pero la amplia difusión que tuvieron sus respectivos libros de viajes sobre España - en forma de traducciones y reediciones- hace que resulten relevantes de por sí, más allá de lo ajustado a la realidad que fuera su contenido.

La imagen que Townsend y Jardine transmiten de España es la de un país en una situación general de persistente decadencia y con pocas posibilidades de despegue. Dicha decadencia, que veían reflejada en el lamentable estado de las infraestructuras, la despoblación interior, el atraso de la agricultura, la manufactura y el comercio, el pobre nivel científico y educativo, e incluso la estructura social — con una aristocracia que no desempeñaba función alguna—, tenía para los viajeros un origen fundamentalmente político, pues su causa última estaba en el mal gobierno y en la falta de libertades asociada a un régimen despótico y al todavía considerable poder de la Inquisición. 
En la identificación de los problemas económicos concretos Townsend y Jardine coinciden esencialmente con los ilustrados, y en especial con Campomanes, cuya obra es su referente básico a la hora de obtener datos sobre aspectos particulares de la economía y determinar los obstáculos específicos a la actividad productiva. Así, las principales cuestiones que se trataron en los debates económicos de la España de la segunda mitad del siglo XVIII tienen su reflejo más o menos explícito - en la obra de ambos viajeros. Sin embargo, Townsend y Jardine eran particularmente críticos con la política proteccionista que primaba en el comercio colonial y que estaba directamente inspirada por el economista asturiano. Además, consideraban que España debía dedicarse sólo al sector primario, y se mostraban muy escépticos frente al reformismo gradualista de la mayor parte de los ilustrados. De hecho, entendían que sin un cambio realmente importante en el sistema político — desde el despotismo arbitrario hacia el gobierno representativo con libertades civiles y tolerancia religiosa-, los intentos de reforma quedarían, en el mejor de los casos, en simples operaciones puntuales de parcheo, por lo que no podría salirse de la situación de decadencia general en la que veían sumido al país.

Los ilustrados españoles, por su parte, tenían una visión de España que era más informada y posibilista que la de los viajeros, y radicalmente distinta en aspectos clave. Primero, mostraban un claro optimismo en relación a las posibilidades de crecimiento de la economía española. Segundo, confiaban en el absolutismo ilustrado - apoyado en la guía de la economía política - como forma de gobierno capaz de conducir al progreso material. Tercero, combinaban un agrarismo más o menos marcado con una firme insistencia en la necesidad de un desarrollo industrial. Y cuarto, apoyaban una política de proteccionismo frente al exterior que se inscribía dentro de un amplio programa de desarrollo económico, el cual incluía también medidas concretas de fomento de la agricultura y la manufactura junto a una gradual liberalización interior y del comercio dentro del Imperio.

\section{BIBLIOGRAFÍA}

ANES, G. (1978): «Tendencias de la producción agrícola en tierras de la Corona de Castilla (siglos XVI a XIX)». Hacienda Pública Española 55, pp. 97-111.

- (1981): Economía e «Ilustración» en la España del siglo XVIII. Barcelona: Ariel.

- (2000): «La economía española en el siglo XVIII», en E. Fuentes Quintana (dir.), Economía y economistas españoles, vol. 3: La ilustración. Barcelona: Círculo de Lectores-Galaxia Gutenberg, pp. 91-184.

AstigarRAGA, J. (2003): Los ilustrados vascos. Ideas, instituciones y reformas económicas en España. Barcelona: Crítica.

AstigarRaga, J., y BARRENECHEA, J. M. (1987): «Estudio preliminar» a N. de Arriquíbar, Recreación política. Vitoria: Instituto Vasco de Estadística, pp. 9-57. 
BACON, F. (1625): «Of travel», en The Essays of Francis Bacon, disponible en texto completo en http://ourworld.compuserve.com/homepages/mike donnelly lotFOUR.htm\#travel.

BARRENECHEA, J. M. (2000): «Valentín de Foronda y el pensamiento económico ilustrado», en E. Fuentes Quintana (dir.), Economía y economistas españoles, vol. 3: La ilustración. Barcelona: Círculo de Lectores-Galaxia Gutenberg, pp. 529-567.

BATLlori, M. (1987): «Prólogo. Presencia de España en la Europa del siglo XVIII. La presencia de España en las capas de la cultura media: los libros de viajes», en Historia de España de Menéndez Pidal, t. XXXI, vol. 1: La época de la Ilustración. El Estado y la cultura (1759-1808). Madrid: Espasa-Calpe, pp. XI-XXV.

CARAnde, R. (1976): «El despotismo ilustrado de los "amigos del país"», en Siete estudios de Historia de España. Barcelona: Ariel, pp. 143-181.

Clavijo y Fajardo, J. (1762): «Modo de que los viajes sean útiles». El Pensador, Madrid, vol. II, pp. 159-190.

De la Iglesia, J. (1994): «Los economistas liberales de Cádiz (1808-1854)». Tesis Doctoral, Madrid: Universidad Complutense.

Delgado RiBAS, J. M. (1995): «Mercado interno versus mercado colonial en la primera industrialización española». Revista de Historia Económica XIII (1), pp. 71-96.

Domínguez Ortiz, A. (1981): Sociedad y Estado en el siglo XVIII español. Barcelona: Ariel.

EloRZA, A. (1970): La ideología liberal en la Ilustración española. Madrid: Taurus.

EnCISO, L. M. (1987): «Los cauces de penetración y difusión en la Península. Los viajeros y las Sociedades Económicas de amigos del País», en Historia de España de Menéndez Pidal, t. XXXI, vol. 1: La época de la Ilustración. El Estado y la cultura (1759-1808). Madrid: Espasa-Calpe, pp. 5-12.

FreIXA, C. (1991): La imagen de España en los viajeros británicos del siglo XVIII. 2 vols., Tesis Doctoral, Barcelona: Dpto. de Geografía Humana, Universidad de Barcelona (microfilmada).

- (1994): «España en las Geografías británicas del siglo XVIII». Estudios Geográficos 214, pp. 59-79.

- (1999): «Imágenes y percepción de la naturaleza en el viajero ilustrado». Scripta Nova. Revista Electrónica de Geografía y Ciencias Sociales 42, pp. 1-16 (http://www.ub.es/geocrit/sn-42.htm).

GARCíA-RoMERAL, C. (1997): Bio-bibliografía de viajeros españoles (siglo XVIII). Madrid: Ollero \& Ramos.

GUERRERO, A. C. (1988): «Los viajeros ingleses y la agricultura española en el siglo XVIII». Agricultura y Sociedad 46, pp. 257-276.

- (1990): Viajeros británicos en la España del siglo XVIII. Madrid: Aguilar.

HERR, R. (1979): España y la revolución del siglo XVIII. Madrid: Aguilar.

JARdine, A. (2001): Cartas de España (1788). Edición crítica de F. Pérez Berenguel, Alicante: Publicaciones de la Universidad de Alicante.

Jovellanos, G. M. de (1953): Diarios. T. I, Oviedo: Instituto de Estudios Asturianos.

- (1954): Diarios. T. II, Oviedo: Instituto de Estudios Asturianos.

- (1983): Informe sobre la Ley Agraria (1795). Madrid: Cátedra.

Kamen, H. (1981): La España de Carlos II. Crítica: Barcelona.

Llombart, V. (1988): «Estudio preliminar»a Rodríguez Campomanes (1988), pp. VIIXLV. 
- (1992): Campomanes, economista y político de Carlos III. Madrid: Alianza.

- (1997): «Convicciones agraristas y actitudes industrialistas. Paradojas de la Ilustración (de Adam Smith a Jovellanos)», en E. Lluch y A. Costas (eds.), Industrialización en España: entusiasmos, desencantos y rechazos. Ensayos en homenaje al profesor Fabián Estapé. Madrid: Civitas, pp. 61-83.

- (2000): «El pensamiento económico de la Ilustración en España», en E. Fuentes Quintana (dir.), Economía y economistas españoles, vol. 3: La ilustración. Barcelona: Círculo de Lectores-Galaxia Gutenberg, pp. 7-89.

Llombart, V., y AstigarRAGA, J. (2000): «Las primeras "antorchas de la economía”: las sociedades económicas de amigos del país en el siglo XVIII», en E. Fuentes Quintana (dir.), Economía y economistas españoles, vol. 3: La ilustración. Barcelona: Círculo de Lectores-Galaxia Gutenberg, pp. 677-707.

LLOPIS, E. (1986): «El agro castellano en el siglo XVII: ¿depresión o "reajustes y readaptaciones"?». Revista de Historia Económica IV (1), pp. 11-37.

Lluch, E. (2000), «El industrialismo en la Corona de Aragón y en la Corona de Castilla», en E. Fuentes Quintana (dir.), Economía y economistas españoles, vol. 3: La ilustración. Barcelona: Círculo de Lectores-Galaxia Gutenberg, pp. 577-581.

LYNCH, J. (2004): La España del siglo XVIII. Barcelona: Crítica.

Mandeville, B. (1997): La fábula de las abejas (1729). Madrid: FCE.

Mestre, A. (1976): Despotismo e Ilustración en España. Barcelona: Ariel.

OCAMPO, J. (2003): «Industrialismo antes de la revolución industrial: la visión de los ilustrados». Cuadernos de Estudios del siglo XVIII 12-13, pp. 93-115.

Perdices, L. (1992): Pablo de Olavide (1725-1803), el ilustrado. Madrid: Editorial Complutense.

- (1996): La economía política de la decadencia de Castilla en el siglo XVII. Madrid: Síntesis.

Perdices, L., y Reeder, J. (2003): Diccionario de Pensamiento Económico en España (1500-2000). Madrid: Síntesis.

Pérez Berenguel, J. F. (2001): «Estudio Preliminar» a Jardine (2001 [1788]), pp. 21-150.

REEDER, J. (1975): «Estudio preliminar» a Rodríguez Campomanes (1975), pp. 7-37.

RoBERTSON, I. (1988a): Los curiosos impertinentes. Viajeros ingleses por España desde la accesión de Carlos III hasta 1855. Barcelona: Serbal/CSIC.

— (1988b): «Prólogo» a Townsend (1988 [1790]).

Rodríguez Braun, C. (1989): La cuestión colonial y la economía clásica. Madrid: Alianza.

RoDRÍGUEZ CAMPOMANES, p. (1975a): Discurso sobre el fomento de la industria popular y Discurso sobre la educación popular de los artesanos y su fomento (1774-1775). Edición de John Reeder, Madrid: Instituto de Estudios Fiscales.

- (1975b): Tratado de la regalía de amortización (1765). Edición de F. Tomás y Valiente, Madrid: Revista de Trabajo.

- (1988): Reflexiones sobre el comercio español de Indias. Edición y estudio preliminar de Vicent Llombart, Madrid: Instituto de Estudios Fiscales-Ministerio de Economía y Hacienda.

SARRAILH, J. (1992): La España Ilustrada de la segunda mitad del siglo XVIII. México: FCE. SHAW, P. (1981): España vista por los ingleses del siglo XVII. Madrid: Sociedad General de Librería. 
LA IMAGEN ECONÓMICA DE LA ESPAÑA DE CARLOS III: JOSEPH TOWNSEND, ALEXANDER...

SMITH, A. (1987): Investigación sobre la naturaleza y causas de la riqueza de las naciones (1776). 2 vols., Vilassar de Mar (Barcelona): Oikos Tau.

Townsend, J. (1786): «A Dissertation on the Poor Laws», disponible en texto completo en la red: http://socserv.socsci.mcmaster.ca/ econ/ugcm/3113/townsend/poorlaw.html.

- (1988): Viaje por España en la época de Carlos III (1786-1787) (1791). Madrid: Turner. 